\title{
Preferences, selection, and value added: A structural approach
}

\author{
Pelin Akyol ${ }^{\mathrm{a}}$, Kala Krishna ${ }^{\mathrm{b}, *}$ \\ a Bilkent University,Turkey \\ b The Pennsylvania State University,United States
}

\section{A R T I C L E I N F O}

\section{JEL classification:}

I20

I21

Keywords:

School choice

School value-added

\begin{abstract}
A B S T R A C T
What do applicants take into consideration when choosing a high school? To what extent do schools contribute to their students' academic success? To answer these questions, we model students' preferences and obtain average valuation placed on each school. We then investigate what drives these valuations by carefully controlling for endogeneity using a set of creative instruments suggested by our model. We find that valuation is based on a school's location, its selectivity as measured by its cutoff score, value added and past performance in university entrance exams. However, cutoffs affect school valuation an order of magnitude more than does value added.
\end{abstract}

"The C student from Princeton earns more than the A student from Podunk not mainly because he has the prestige of a Princeton degree, but merely because he is abler. The golden touch is possessed not by the Ivy League College, but by its students."

Shane Hunt, "Income Determinants for College Graduates and the Return to Educational Investment," Ph.D. thesis, Yale University, 1963, p. 56.

\section{Introduction}

In much of the world, elite schools are established and very often subsidized by the government. Entry into these "exam" schools is based on performance in open competitive entrance exams. Applicants leave no stone unturned in their quest for higher scores on these entrance exams, creating enormous stress. The belief seems to be that getting into these schools is valuable, presumably because future outcomes are better in this event. Students, it is argued, will do better by going to an exam school where they are challenged by more difficult material and exposed to better peers. What actually happens? Students of these elite exam high schools, without a doubt, do better on college entrance exams and are more likely to be placed at the best university programs. But is this due to selection or value-added by these schools? It is quite possible that the success of students from exam schools creates the belief that these schools add value. This belief results in better students sorting into exam schools so that students from these schools do better, which perpetuates the belief system.

The usual way of ranking schools is in terms of their selectivity, how hard they are to get into in terms of some performance measure like the SATs in the US, ${ }^{1}$ or in terms of how well students who graduate from them do as measured by wages, eminence in

\footnotetext{
* Corresponding author.

E-mail addresses: pelina@bilkent.edu.tr (P. Akyol), kmk4@psu.edu (K. Krishna).

${ }^{1}$ Schools are sometimes less than honest: some inflate their statistics on the performance of their entering class. Some schools manipulate the system by keeping their class size small, thereby having high SATs and looking very selective. See "Academic integrity should count in rankings" in the Kansas City Star, 2/8/2013. http://www.centredaily.com/2013/02/12/3499088/editorial-academic-integrity-should.html
} 
later life, or admission into further schooling. However, schools may do well in all of these dimensions merely because they admit good students and not because they provide value added and thereby improve the performance of the students they admit. ${ }^{2}$ How can we control for such selection and estimate value added? What do students seem to value? Can we model and estimate their preferences? These are the questions we try to address.

Turkey is a good place to look for answers to these questions for a number of reasons. To begin with, the Turkish admissions system is exam-driven. Admissions are rationed on the basis of performance on open competitive national central exams at the high school and university level. This eliminates incentive problems when there are a large number of students. ${ }^{3}$ Second, as education is highly subsidized in public institutions, educational options outside the country or at private institutions are much more expensive so that these exams are taken seriously by the applicants. When the stakes are high, as in Turkey, it is less likely that outcomes are driven just by noise.

We develop a way to answer the questions of interest by taking a more structural approach than much of the literature. The structure imposed allows us to economize on the data requirements. Our data consists of information on all high schools (Exam Schools) in Turkey which admit students on the basis of an open competitive exam administered at the end of middle school. Not all middle schoolers take this exam as it is voluntary. We obtained (from public sources) the admission cutoff scores of each exam school, the number of seats in each such school, and the overall distribution of scores of students who chose to take this exam. For one school only, we also have the distribution of scores of admitted students. We also have the mean performance of students in each exam high school in the university entrance exam. We would like to emphasize that we do not have individual level data on performance in the high school (or university entrance) exam or on stated preferences for high schools.

We use this data in Section 3 to estimate a nested logit model of preferences over high schools, taking into account that exam schools only admit the highest scoring students who apply. Thus, students choose their best school from schools whose cutoff is below their score. We estimate preferences in two steps. First, by using information on the minimum cutoff scores, we derive the demand for each school, conditional on the correlation of shocks within a nest. We obtain the mean valuation for each school by setting demand equal to the number of available seats and solving for mean valuation. Second, we pin down the correlation of shocks within a nest using information on the maximum and minimum cutoff scores in each school. This twist, to our knowledge, is novel. The idea is quite simple. If preference shocks are perfectly correlated within a nest, then preferences are purely vertical and the minimum score in the most valued school in the nest cannot be lower than the maximum score in the second most valued school in the nest. Thus, the extent of overlap in the scores between schools within a nest identifies the correlation in preference shocks in the nest.

Finally, in Section 3, to see what applicants care about in a school, we regress the mean valuation of schools on the schools' characteristics (its location, size, mean performance in the verbal and quantitative parts of the university entrance exam, type of school, and the cutoff score). The error term, which is meant to capture shocks to school valuations, is likely to be correlated with the cutoff, as greater valuations raise demand and hence the cutoff, biasing the estimates upwards. We use a clever instrument suggested by our model to correct for endogeneity bias. We find that selectivity does indeed seem to raise valuations.

Section 4 focuses on value added. In this section we restrict attention to a subset of schools (Science high schools). To understand the value added by a school, we use the data on the overall distribution of scores on the high school entrance exam, along with the estimated preference parameters, to allocate students to high schools and obtain the simulated distribution of students' scores on the high school entrance exam in each school. We then compare the mean of the simulated distribution for each school to its mean score in the University Entrance Exam after standardizing the scores. This gives a (possibly contaminated by mean reversion) estimate of the value-added by a school. Mean reversion is likely to be especially severe at the top and bottom of the school hierarchy as it is a consequence of randomness in performance. Students in the best (worst) schools disproportionately include those who are just lucky (unlucky) so that their performance in the university entrance exams will tend to be below (above) that in the high school entrance exams even if there is zero value added. We use simulation-based methods as well as information on each student in a single school to estimate the average value-added by a school, while controlling for mean reversion. Note that the extent of the mean reversion depends on both preferences and the extent of noise in the high school entrance exam score so that correcting for it can only be done by taking a structural approach. Finally, we ask if value added also drives mean valuation of a school.

Our results show that highly valued schools do not all have high value-added. Some have negative value added, while others have positive value added. Our estimates suggest that students like more selective schools so that better students, who have more options open to them, sort into these schools. We also find that they also care about the value added by the school, but its importance (in a standardized regression) is far less than that of the cutoff score. Consequently, even when schools do not add value to the students (in terms of their performance on the university entrance exam) they attract good students, providing an advantage to incumbents and an impediment to entry and the functioning of the market.

A major contribution of our paper is to relate the valuations placed on schools to measures of school characteristics such as selectivity, facilities, location and value added by the school. It is important to understand what lies behind preferences. If preferences seem to be driven by selectivity alone, selective schools need not be those that are adding the most value and circular causation will drive rankings. Preferences may be unrelated to school performance (i.e., value added) either because it is hard to

\footnotetext{
${ }^{2}$ There has recently been considerable effort in determining value-added by a school as part of the accountability in the No Child Left Behind legislation. See Darling-Hammond et al. (2012) for a critique of the approach usually taken.

${ }^{3}$ Students prefer to report their true preferences, no matter what other students report as they take the cutoffs as given.
} 
observe, or because of other advantages of selective schools like consumption or network value. If the former, a case could be made for publicly providing value added school by school.

Exam schools in Turkey are given more funding per student, and they have higher teacher to student ratios. The better off are also more likely to be able to get into these schools (For example, see Caner and Okten, 2013) so that such funding is likely to be a regressive force. ${ }^{4}$ Providing funding based on value-added by a school may make such funding less regressive, as well as better align the incentives of schools and society. Though our data is on Turkey, the issues raised in this paper are of universal interest.

We proceed as follows. First, we relate our work to the literature. In Section 2, we provide the necessary background regarding the Turkish system and the data. Section 3 lays out the model, the estimation of preferences and the first results on what seems to drive valuations. In Section 4, we estimate the value-added by the schools and examine whether it is related to valuations. Then, we conclude. Additional figures, tables and details about the estimation strategy can be found in the Appendix.

\subsection{The literature}

There is a large literature that deals with school choice and school effects in the US, as well as in other developed and developing countries. While the evidence on the effect of attending more selective schools on students' academic achievement is mixed, one possible interpretation is that just attending a more selective school is not enough to improve future performance. An essential input might also be the motivation of students. This could be manifested in the data as they are choosing to attend a more selective school, despite it being harder in some dimension for them to do so.

In the US, the consensus seems to be that expanding school options, via having exam schools or having lotteries that allow the winners more school options, need not have much of an impact on a student's academic achievement. Abdulkadiroğlu et al. (2014) and Dobbie and Fryer Jr (2011) find going to exam schools has little effect on academic achievements using a RegressionDiscontinuity approach in Boston and New York, respectively. Cullen et al. $(2005,2006)$ use data from randomized lotteries that determine the allocation of students in the Chicago public school system. Students who win the lottery have more options open to them and so can attend schools more consistent with their tastes and hence are better off. ${ }^{5}$ They find that winning this lottery does not improve students' academic performance. In contrast to work that finds little effect of expanding school options, Hastings et al. (2012) use U.S. data from a low income urban school district and find that winning this lottery has a positive and significant effect on both student attendance after winning the lottery but before going to the new school, and on performance later on. Clark (2010) investigates the effect of attending a selective high school (Grammar School) in the UK (where selection is based on a test given at age 11 and primary school merit) and finds no significant effect on performance in courses taken by students, although the probability of attending a university is positively affected.

Dale and Krueger $(2002,2011)$ look at the effect of attending elite colleges on labor market outcomes. They control for selection by controlling for the colleges to which the student applied and was accepted. The former provides an indication of how the student sees himself, while the latter provides a way of controlling for how the colleges rank the student. Intuitively, the effect of selective schools on outcomes is identified by the performance of students who go to a less selective school despite being admitted to a more selective one, relative to those who go to the more selective one. Of course, if this choice is based on unobservables, this estimate would be biased. ${ }^{6}$ They find that black and Hispanic students as well as students from disadvantaged backgrounds (less-educated or low-income families) do seem to gain from attending elite colleges. However, for most students the effect is small and fades over time.

Duflo et al. (2011) emphasize an important additional channel that may induce heterogeneity in effects. If, for example, teachers at a top ranked school direct instruction towards the top, ignoring weaker students, better students in the class may gain, while worse ones may lose. In such cases the value added of a school can vary by student ability and tracking may help teachers target students.

Card and Giuliano (2014) look at the effect of being in gifted programs. They find that high IQ students, to whom these programs are often targeted, do not seem to gain from such programs. However, students who miss the IQ thresholds but scored highest among their school/grade cohort in state-wide achievement tests in the previous year do gain. Their work suggests that "a separate classroom environment is more effective for students selected on past achievement - particularly disadvantaged students who are often excluded from gifted and talented programs."

In contrast to these results, Pop-Eleches and Urquiola (2013) and Kirabo Jackson (2010) estimate the effect of elite school attendance in Romania and Trinidad and Tobago, respectively. They find a large positive effect on students' exam performance in the university entrance exams. This could be because students who go to elite schools in these countries are more motivated to succeed than those going to elite schools in richer countries.

From the school choice literature, Hastings et al. (2008) and Burgess et al. (2009) investigate what parents care about in a school using data from the Charlotte-Mecklenburg School District and Millennium Cohort Study (UK), respectively. Hastings et al. (2008) take a structural approach and estimate a mixed logit model of preferences. A major contribution of their work is to use information on the stated preferences for schools and compare these to what was available to them to back out the weight placed on factors like academics, distance from home, and so on. They are then able to see whether the impact of a school differs according to "type". They

\footnotetext{
${ }^{4}$ This regressive nature is common across countries as the better off are advantaged in many ways.

5 The schools they choose may be those that add value through delivering higher achievement levels, better peers and more resources, or not.

${ }^{6}$ For example, if confident students go to the selective school and less confident ones do not, and confident students do better, the effect of selective schools would be overestimated.
} 
find that students who put a high value on academics in so much as they choose to go to "supposedly good" schools that are further away, do better from being there than students who attend just because they are close to the school. For this reason, reduced form effects estimated for attending "good" schools could be biased when such selection is not properly accounted for. If students in developing countries place greater value on good schools than do students from developed countries, this insight could explain why we see such different results for attending better schools in the two. Burgess et al. (2009) also compare the first choice school, to the set that was available (constructed by the authors by using students' residence areas) and estimate trade-offs between school characteristics.

An advantage of the slightly more structural approach taken here is that we examine the whole process and not just one of its components in the estimation. Our approach allows us to separate between preferences over schools (based on their observable attributes) and their value added. Moreover, despite the lack of panel data, i.e., not having the high school entrance exam score and the college entrance exam score for each student, we show how one can use fairly limited data on each high school, along with data on university entrance exam takers along with the model, to get around this deficiency. That is to say, our approach allows us to economize on data in the estimation which extends the ability to look at policy issues, as outcomes may differ across countries. Of course, the applicability of our method depends on certain institutional characteristics, such as priority by score in the allocation of students to high schools, and the existence of uniform school leaving or university entrance exams. While our approach has many limitations, for example, it does not allow us to look at whether attending elite exam schools has heterogeneous effects, nor does it let us look at long term effects (which may be large even if short term ones are not ${ }^{7}$ ) as in Chetty et al. (2014a), it does provide a way to do a lot with relatively little data.

\section{Background}

In Turkey, competitive exams are everywhere. Unless a student chooses to attend a regular public high school, he must take a centralized exam at the end of 8th grade to get into an "exam school". These are analogous to magnet schools in the US, though the competition for placement into them is national and widespread, rather than local as in the US. After high school there is an open competitive university entrance exam given every year. Most students go to cram schools (dershanes) to prepare for the university entrance exam. Much of high school is also spent preparing students for this exam. In fact, it has been argued that at least in Turkey, cram schools weaken the formal schooling system as students substitute cram schools (dershanes) for high school (see Tansel and Bircan, 2006). If exam schools, in fact, have little value-added, then the system itself may have adverse welfare effects. This is especially so if these elite exam schools are subsidized relative to the alternatives as is often the case. ${ }^{8}$ In this event, students expend possibly wasteful effort to capture these rents which has a welfare cost. ${ }^{9}$

Students from exam schools do perform much better in university entrance exams. Fig. 1 shows the distribution of average scores (ÖSS-SAY) in the university entrance exam of science track students coming from the different kinds of high schools. Science high schools are clearly doing better, followed by the almost equally selective Anatolian high schools, while regular public schools seem to do the worst. However, this says little about the contribution of exam schools in terms of value-added.

\subsection{The institutional structure}

The educational system in Turkey is regulated by the Ministry of Education. All children between the ages of 6 and 14 must go to school. At 14 they take the high school entrance exam (OKS) if they want to be placed in public exam schools. Performance on this exam determines the options open to a student. The better the performance, the greater the number of schools with a cutoff score below what the student has obtained. There are four types of public exam schools: Anatolian high schools, Anatolian Teacher Training high schools, Science high schools, and Anatolian Vocational high schools.

Anatolian high schools place a strong emphasis on foreign language education although their specific goals may vary across the different types of Anatolian schools. The main goal of Anatolian high schools is to prepare their students for higher education while teaching them a foreign language at a level that allows them to follow scientific and technological developments in the world. Anatolian Vocational high schools aim to equip their students with skills for certain professions and prepare them both for the labor market and higher education. Anatolian Teacher Training high schools train their students to become teachers though they can choose other paths as well.

The most prestigious of the exam schools are the Science high schools. These were established in the mid-1980s to educate the future scientists of Turkey and initially accepted very few students. Over the next decade, the success of their students on the university entrance exams, as well as the rigorous education these schools were famous for, created considerable demand for these schools and they spread throughout the country.

In public high schools, students can choose between four tracks: the Science track, the Turkish-Math track, the Social Science track and the Language track. They make this choice after ninth grade. In Science high schools they must take the science track. In Anatolian Vocational high schools there are no tracks, which put them a little outside the mainstream. All of this is depicted in Fig. 2.

After eleventh grade, students who wish to pursue higher education take a centralized nationwide university entrance exam (ÖSS), which is conducted by the Student Selection and Placement Center (ÖSYM). There are no selection issues here: data (from the

\footnotetext{
${ }^{7}$ Zimmerman (2014) suggests that elite school attendance may have long term impacts via networks and referrals.

8 The best teachers are allocated to these schools, their facilities are better, and their class sizes are smaller than that of regular schools. In addition, Caner and Okten (2013) show that school subsidies are regressive as better off students tend to do better on exams and so go to better schools which are more highly subsidized.

${ }^{9}$ See Krishna and Tarasov (2013) for more on this subject.
} 


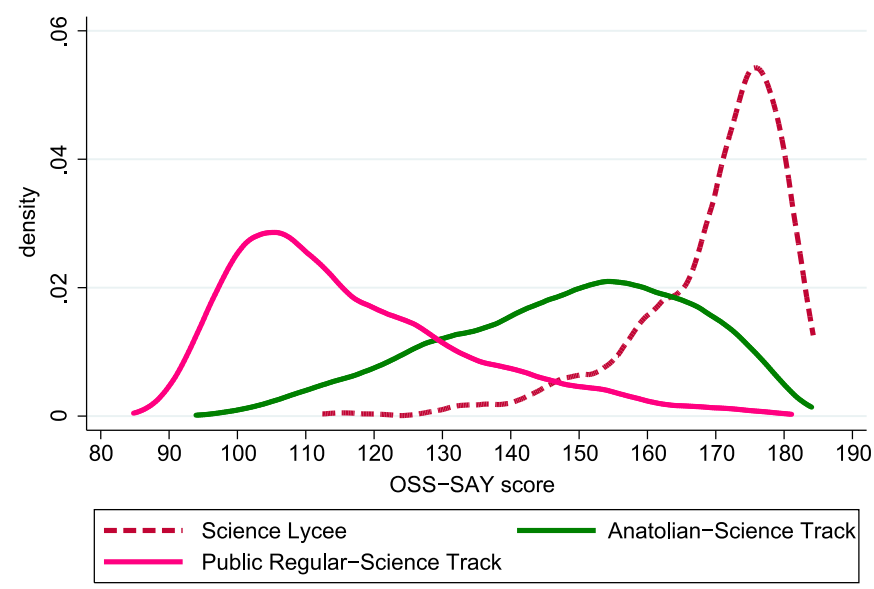

Fig. 1. Distribution of ÖSS-SAY score.

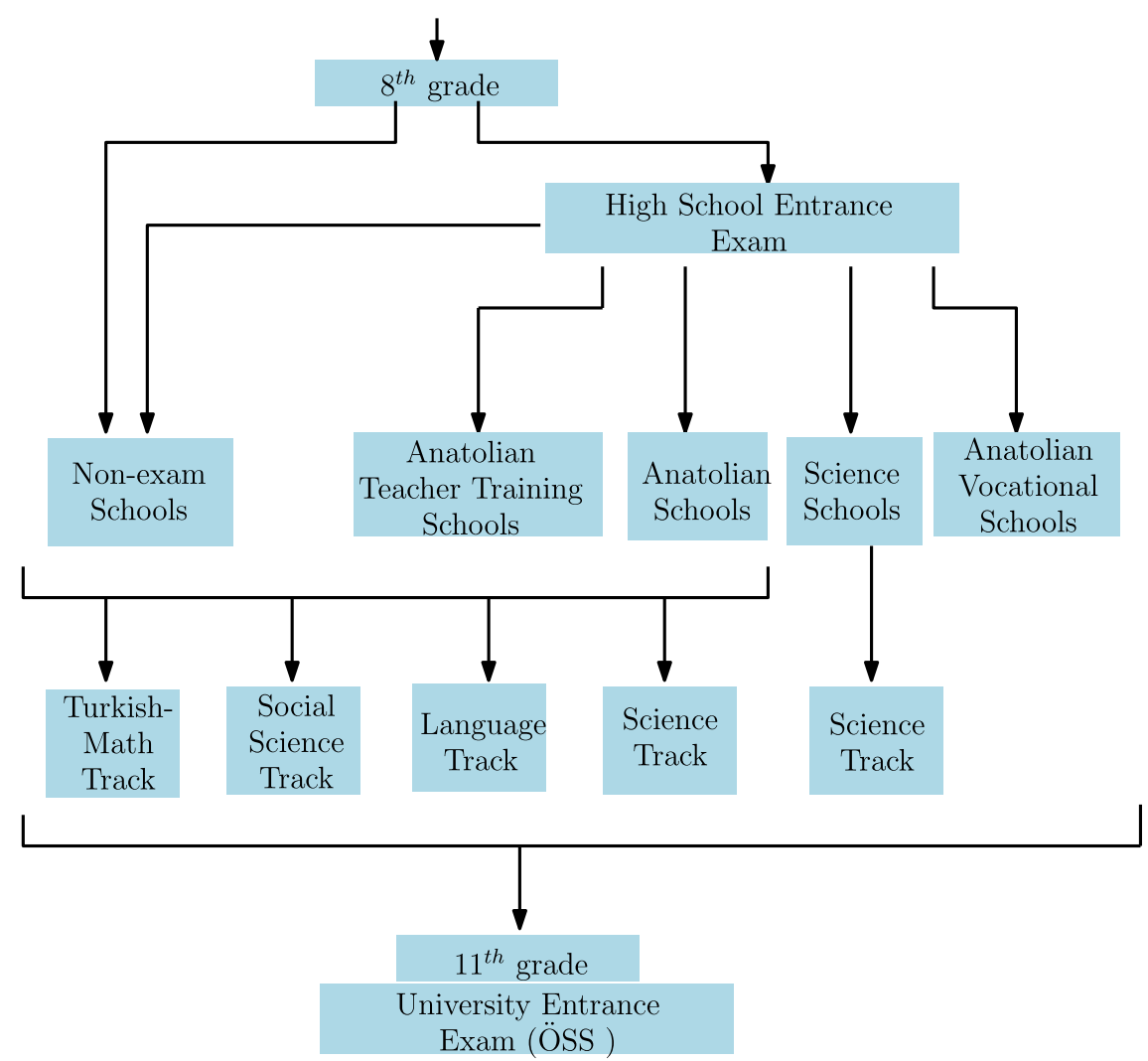

Fig. 2. Education system in Turkey.

National Education Statistics Bureau) on the number of high school graduates and data on the number of students taking the university entrance exam for the first time (from reports released by ÖSYM) show that these two are very close to each other. This exam is highly competitive and placement of students into colleges is based on their ÖSS score, high school grade point average (GPA), and their preferences.

Below, we use high school and university entrance exam scores to infer the value-added of schools. For this reason, it is important to explain what these exams consist of and how similar they are. Both high school and university entrance exams are multiple choice tests that are held once a year. The high school entrance exam is taken by students at the end of eighth grade. There are four tests, Turkish, social science, math, and science, with 25 questions on each test. Students are given 120 min to answer the 100 questions. The University entrance exam is similar. It is a nationwide central exam with four parts, Turkish, social science, math, and science, 
with 45 questions in each part. Students are given $180 \mathrm{~min}$. The questions on both exams are based on the school curriculum and are meant to measure the ability to use the concepts taught in school. To discourage guessing, there is negative marking for incorrect answers in both exams.

\subsection{The data}

The data we use come from several public sources. To measure students' academic performance at the end of high school, we rely on information on the performance of each school on the university entrance exam from 2002 to 2007. This information is published by ÖSYM and is made available to schools and families so that they are informed about the standing of each school. The information includes the number of students who took university entrance exam from each school, as well as the mean and standard deviation of their scores in each field of the exam.

A student's performance in the high school entrance exam is seen as a (noisy) measure of his performance prior to attending high school. We obtained data on the minimum and maximum admission scores and on the number of seats in 2001 for each exam high school from the Ministry of Education's website. ${ }^{10}$ The summary statistics for these variables are presented in Table A6. We also collected data on the average ÖSS performance of each high school on each part of the exam in the previous year, 2000, from ÖSYM's Results booklet for that year, which is publicly available from their website. This is used as one possible quality dimension along which schools vary. Additional high school characteristics were collected from the Ministry of Education's website (education language, dormitory availability, and location) and the high schools' websites (age of the schools). We use this data along with the score distribution of all students who took the high school entrance exam in 2005 (see Table A7) in our analysis below. Ideally we would have liked to have this information for 2001, but as this was not available and as these distributions are very stable, we use data from 2005.

In the next section we show how to use information on the allocation process, seats available, the distribution of scores overall on the high school entrance exam, and the preference structure to back out the mean valuation placed on each high school.

\section{The model}

Seats in public exam schools are allocated according to students' preferences and their performance on a centralized exam (conducted once a year). All schools have an identical ranking over students based on their test scores. Each exam school has a fixed quota, $q_{j}$, which is exogenously determined. ${ }^{11}$ The allocation process basically assigns students to schools according to their stated preferences, with higher scoring students placed before lower scoring ones. Students know past cutoffs for schools when they put down their preferences. They are allowed to put down up to 12 schools. $^{12}$

We model preferences as follows. Student $i$ 's utility from attending school $j$ takes the form

$$
U_{i j}\left(X_{j}, \xi_{j}, \varepsilon_{i j} ; \beta\right)=\beta X_{j}+\xi_{j}+\varepsilon_{i j}
$$

where $X_{j}$ are the observed school characteristics, $\xi_{j}$ are the unobserved school characteristics, and $\varepsilon_{i j}$ is a random variable which has a Generalized Extreme Value (GEV) distribution. Let $\delta_{j}$ denote the school specific mean valuation where

$$
\delta_{j}=\beta X_{j}+\xi_{j}
$$

so that

$$
U_{i j}\left(X_{j}, \xi_{j}, \varepsilon_{i j} ; \beta\right)=\delta_{j}+\varepsilon_{i j}
$$

This structure implies that variation in individual preferences comes from the error term, conditional on the students having the same feasible choice set. ${ }^{13}$ Preference shocks are allowed to be correlated for the alternatives in the same nest. Otherwise, they are assumed to be independent.

In general, the cumulative distribution function of $\varepsilon=\left\langle\varepsilon_{i 0}, \varepsilon_{i 1}, \ldots, \varepsilon_{i N}\right\rangle$ is given by

$$
H\left(\varepsilon_{i 0}, \varepsilon_{i 1}, \ldots, \varepsilon_{i N}\right)=\exp \left(-\sum_{k=1}^{K}\left(\sum_{j \in B_{k}} \exp \left(-\frac{\varepsilon_{i j}}{\lambda_{k}}\right)\right)^{\lambda_{k}}\right)
$$

where $B_{k}$ is the set of alternatives within nest $k, K$ is the number of nests, and $\lambda_{k}$ measures the degree of independence among the

\footnotetext{
10 This data was collected using the website http://archive.org/web/web.php, which provides previous versions of websites.

${ }^{11}$ In general, the seats available are close to the size of the graduating class as schools are capacity constrained.

12 Students do face a location restriction in listing their Anatolian high school preferences. They are not allowed to list preferences on Anatolian high schools in Ankara, İstanbul, İzmir, and their current city: they have to pick one of these locations and make all their Anatolian high school preferences from their chosen location. However, if preferences are stated after the score is known, and cutoffs are stable over time (as in our setting) this restriction should not have any impact. A student would put his most preferred school with a cutoff below his score at the top of his list and be assigned there.

${ }^{13}$ In our model, we do not incorporate heterogeneity in valuations depending on students' score or other background characteristics as we do not have information on individual student's preferences. However, the choice set for each student depends on his score so that individuals with different scores make very different choices. With better data on students' scores, background characteristics, stated preferences and high school placement, we could allow valuations to depend on individual characteristics. Moreover, with such data we could do a much better job estimating school value-added and even allow for possible heterogeneous treatment effects.
} 


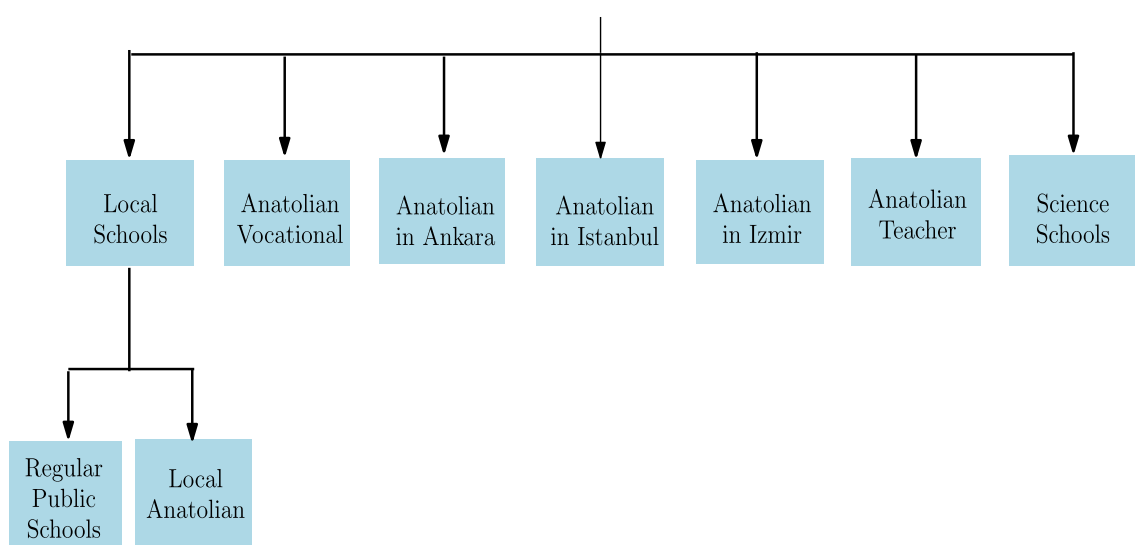

Fig. 3. School choice in Turkey.

alternatives within nest $k$ (see Train, 2009). As $\lambda_{k}$ increases, the correlation between alternatives in nest $k$ decreases. If $\lambda_{k}$ is equal to 1 , there is no correlation between alternatives within nest $k$, whereas as $\lambda_{k}$ goes to 0 , there is perfect correlation among all alternatives in the same nest. In this case, the choice of alternatives for any individual is driven by the $\delta_{j}$ component alone so that there is pure vertical differentiation among schools in a nest.

We partition the set of high schools in Turkey according to their type and location. Fig. 3 shows the nesting structure we adopt. Since we want to allow for vertical and horizontal differentiation, it makes sense to put similar schools in the same nest. Thus, at the upper level of the nest, students have seven options: Science high schools, Anatolian Teacher Training high schools, Anatolian high schools in Ankara, in İstanbul and in İzmir, Anatolian Vocational high schools, and the local school option. The local school option for a student includes a local Anatolian school and a public regular high school which is modeled as the outside option. Since computational intensity will increase with the size of the choice set, we aggregate Anatolian Vocational high schools into five subgroups according to their types with seats equal to the sum of seats of schools in that subgroup. We define the maximum and minimum score of each subgroup as the maximum and minimum of the cutoff scores of the schools in that subgroup. Other nests include all schools in Turkey of a given type: 91 Teacher Training high schools, 48 Science high schools, 24 Anatolian high schools in Ankara, 38 Anatolian high schools in İ stanbul, and 18 Anatolian high schools in İzmir. ${ }^{14}$ Thus, we have 226 options overall. ${ }^{15}$

Each student chooses a school that maximizes his utility given his feasible set of schools, which is determined by his own score, $s_{i}$, and the cutoff scores of each school

$$
\max _{j \in \mathcal{F}_{i}} U_{i j}\left(X_{j}, \xi_{j}, \varepsilon_{i j} ; \beta\right)
$$

where

$$
\mathcal{F}_{i}=\left\{j: c_{j} \leq s_{i}\right\}
$$

The feasible set of a student, $\mathcal{F}_{i}$, includes all the schools whose cutoff score is below the student's score. Given the demand for each school and the number of seats available, the cutoff score, $c_{j}$, is endogenously determined in equilibrium.

Let the set of $N$ schools be partitioned into $K$ mutually exclusive sets (nests) where the elements of each of these sets correspond to schools within that nest. For example, $B_{k}$, where $k=1,2, \ldots, K$, would have all schools that are in nest $k$ as its elements. If there were no rationing, the probability that school $j$ in nest $k$ was chosen by student $i$ would be given by ${ }^{16}$

$$
P_{i j}(\boldsymbol{\delta}, \lambda)=\frac{\exp \left(\frac{\delta_{j}}{\lambda_{k}}\right)\left(\sum_{l \in B_{k}} \exp \left(\frac{\delta_{l}}{\lambda_{k}}\right)\right)^{\lambda_{k}-1}}{\sum_{n=1}^{K}\left(\sum_{l \in B_{n}} \exp \left(\frac{\delta_{l}}{\lambda_{n}}\right)\right)^{\lambda_{n}}}
$$

which would be equivalent to the fraction of students whose best alternative was alternative $j$.

However, students' choices are constrained by the cutoff scores in each school, $c_{j}$, and by their own exam performance, $s_{i}$. Suppose that there are $N+1$ choices (including the outside option) and let the cutoff scores for each alternative be ordered in ascending order:

$$
c_{0}=0<c_{1}<c_{2}<\cdots<c_{N-1}<c_{N}
$$

\footnotetext{
${ }^{14}$ These schools are located in the center of the Ankara, İstanbul, and İzmir. Anatolian high schools located in a town in the provinces are defined as local Anatolian high schools by Ministry of Education.

${ }^{15}$ We ignore private exam high schools as they comprise less than $5 \%$ of the total and there is no data on them.

${ }^{16}$ See Train (2009, Chapter 4) for the derivation of $P_{i j}$.
} 
where 0 indexes the outside option. Students whose score is in the interval $\left[c_{m}, c_{m+1}\right)$ have the first $m$ schools in their feasible choice set and we call this interval $I_{m}$. Similarly, students whose scores are below $c_{1}$ have scores in $I_{0}$ and have their choice set containing only the outside option, while students with $s_{i} \geq c_{N}$ get to choose from all the $N+1$ alternatives and have scores in $I_{N}$. Thus, the probability that student $i$ with a score in $I_{j}$ chooses school $t, t \leq j$, in nest $k$ from his feasible set will be

$$
P_{j t(k)}(\boldsymbol{\delta}, \lambda)=\left\{\frac{\exp \left(\frac{\delta_{t}}{\lambda_{k}}\right)\left(\sum_{l \in B_{k}\left(I_{j}\right)} \exp \left(\frac{\delta_{l}}{\lambda_{k}}\right)\right)^{\lambda_{k}-1}}{\sum_{n=1}^{K_{j}}\left(\sum_{l \in B_{n}\left(I_{j}\right)} \exp \left(\frac{\delta_{l}}{\lambda_{n}}\right)\right)^{\lambda_{n}}} \text { if } s_{i} \in I_{j}\right\}
$$

where bold variables denote vectors and where $B_{k}\left(I_{j}\right)$ denotes the restriction placed on the elements of nest $k$ when the individuals' score is in the interval $I_{j} . \lambda_{k}$ is the extent of independence between alternatives in nest $k$, and $K_{j}$ is the total number of nests available to a student whose score is in the interval $I_{j}$.

Aggregate demand for each school will thus depend on the distribution of scores, $F(s)$, the minimum entry cutoff scores of all other schools whose cutoff score is higher, and the observed and unobserved characteristics of all schools. Using the equilibrium cutoff scores and the students' score distribution we can get the density of students that are eligible for admission to each school.

For simplicity, we will write the demand function for school $j$ in nest $s, d_{j(s)}(\delta, \lambda)$, as $d_{j(s)}$. The demand for school $N$, the best school, which is in nest $k$ comes only from those in $I_{N}$ :

$$
d_{N(k)}=P_{N N(k)}(\boldsymbol{\delta}, \lambda)\left[1-F\left(c_{N}\right)\right]
$$

Only students with scores above $c_{N}$ have the option to be in school $N$ which gives the term $\left[1-F\left(c_{N}\right)\right]$. In addition, $N$ in nest $k$ has to be their most preferred school; hence the term $P_{N N(k)}(\delta, \lambda)$. Similarly, the demand for school $j$ which is in nest $s$ comes from those in $I_{j}, \ldots I_{N}$ :

$$
\begin{aligned}
& d_{j(s)}=P_{N j(s)}(\boldsymbol{\delta}, \lambda)\left[1-F\left(c_{N}\right)\right]+P_{(N-1) j(s)}(\boldsymbol{\delta}, \lambda)\left[F\left(c_{N}\right)-F\left(c_{N-1}\right)\right]+\cdots+P_{(j) j(s)}(\boldsymbol{\delta}, \\
& \lambda)\left[F\left(c_{j+1}\right)-F\left(c_{j}\right)\right]=\sum_{w=j}^{N-1} P_{w j(s)}\left[F\left(c_{w+1}\right)-F\left(c_{w}\right)\right]+P_{N j(s)}(\boldsymbol{\delta}, \lambda)\left[1-F\left(c_{N}\right)\right]
\end{aligned}
$$

Students with higher scores have more options open to them which is what makes higher scores valuable to a student in this setting.

\subsection{Estimation strategy and results}

Given the preference parameters and the number of seats in each school, the real world cutoffs are determined by setting the demand for seats, as explained above, equal to their supply and obtaining the market clearing score cutoffs. This is not what we will do. For us, the cutoffs and the number of seats are data. We want to use this data and the nesting structure imposed to obtain the preference parameters. In particular, we want to estimate the coefficients of school characteristics $(\beta)$ and the parameter vector $\lambda$, where $\lambda=\left[\lambda_{1}, \lambda_{2}, \ldots, \lambda_{K}\right]$, that best fit the data and respect the solution of the model that equates demand (d) with supply (q).

We do this in two steps. In Step 1 , we back out the values of $\delta_{j}$ for each school $j$ for a given $\lambda$. In essence, the minimum cutoff in each school denoted by the vector $\mathbf{c}=\left(c_{1}, . . c_{N}\right)$, the number of seats in each school denoted by the vector $\mathbf{q}=\left(q_{1}, . . q_{N}\right)$, together with the market clearing conditions of the model, pin down the mean valuation of each school for a given vector, $\lambda=\left(\lambda_{1}, \ldots \lambda_{K}\right)$. In step 2 , we find $\lambda$ so as to best match the extent of overlap in the scores of schools in the same nest. A higher correlation in the errors within a nest means that there is less of a role for preference shocks to play in choice, so that preferences are driven by the non-random terms. This corresponds to having more of a vertical preference structure. As a result there is less overlap in the range of student scores across schools in a nest. If there is perfect correlation, the maximum score in a worse school will be less than the minimum score in a better one. Following this, we relate our estimates of $\delta_{j}$ to the characteristics of each school to see what drives the preferences for schools.

We do not use the standard nested logit setup because the cutoff score constrains choice. Only those students with scores above the cutoff for a school have the option of attending it. Had we ignored this constraint, we would have obtained biased estimates of $\delta_{j}$. For example, small and selective colleges would be wrongly seen as undesirable. ${ }^{17}$

\subsection{Step 1: mean valuations conditional on $\lambda$}

Our model includes unobserved school characteristics, and these unobserved characteristics enter the demand function nonlinearly, which complicates the estimation process. Berry (1994) proposed a method to transform the demand functions so that unobserved school characteristics appear as school fixed effects. By normalizing the value of the outside option to zero, $\delta_{0}=0$, we have $N$ demand equations with $N$ unknowns. This permits us to get the vector $\delta(\mathbf{q}, \mathbf{c}, \lambda)$ for given vectors $\mathbf{q}$ and $\mathbf{c}$, conditional on a

\footnotetext{
${ }^{17}$ There is a growing literature on the structural estimation of matching models that uses data on who is matched with whom (see Fox, 2009). Since we do not observe all matches and only see the minimum and maximum scores associated with each school as well as the number of seats, our approach has to differ from theirs.
} 


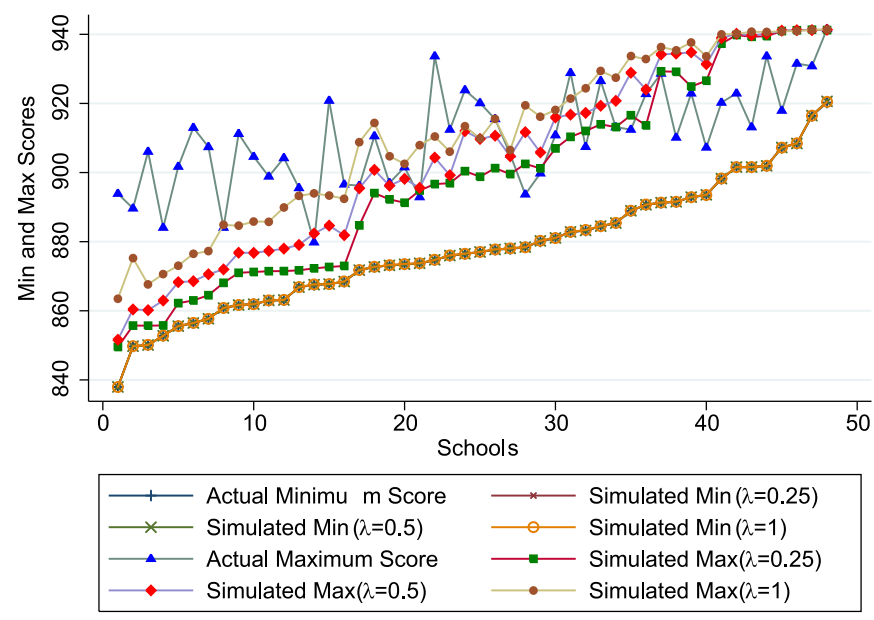

Fig. 4. Real and simulated cutoff scores for $\lambda=0.25,0.5,1$.

vector $\lambda$ such that

$$
\mathbf{q}=\mathbf{d}(\boldsymbol{\delta}(\mathbf{q}, \mathbf{c}, \lambda), \lambda) \text {. }
$$

On the left-hand side we have supply of seats, and on the right-hand side we have the demand for seats for a given vector of mean school valuations and school cutoffs (denoted by $\delta$ and $\mathbf{c}$, respectively) and correlation of shocks within nests $(\lambda)$. For a given $\lambda$, and with $\mathbf{q}$ and $\mathbf{c}$ coming from the data, we can invert the above to obtain $\delta(\mathbf{q}, \mathbf{c}, \lambda)$. We cannot solve for $\delta(q, c, \lambda)$ analytically as done in some of the models in Berry (1994). Our setup is closer to that in Bresnahan et al. (1997) who solve the system numerically as we do. Berry (1994) shows that if the market share function is everywhere differentiable with respect to $\delta$, and its derivatives satisfy the strict equalities: $\frac{\partial d_{j}}{\partial \delta_{j}}>0$ and $\frac{\partial d_{j}}{\partial \delta_{k}}<0$ for $k \neq j$, the market share function is invertible and unique. As our demand function satisfies these conditions, our numerical solution for $\delta(q, c, \lambda)$ is unique.

\subsection{Step 2: pinning down $\lambda$}

Once we get $\delta(\mathbf{q}, \mathbf{c}, \lambda)$, we can specify individual $i$ 's utility from alternative $j$ as

$$
U_{i j}\left(\lambda, \mathbf{q}, \varepsilon_{i j}\right)=\delta_{j}(\mathbf{q}, \mathbf{c}, \lambda)+\varepsilon_{i j}
$$

At this stage, the only unknown in the utility function is the vector $\lambda$. As the $\lambda$ for a nest falls, the correlation of the utility shock within the nest will increase. In the extreme case, when the correlation is perfect, if one agent values a particular school highly so do all other agents, which can be interpreted as pure vertical differentiation. In this case, there will be no overlap in the score distributions of different schools within the nest. If correlation is low, then some students will choose one school and others will choose another and there will be overlap in the score distributions. The extent of overlap in the minimum and maximum scores of schools that are next to each other in cutoffs within a nest helps to pin down the $\lambda$ in the nest.

Fig. 4 shows how different values of $\lambda$ affect the fit of the model to the data for the Science high school nest. For each $\lambda$, the simulated minimum scores lie exactly on top of the actual minimum scores as depicted in Fig. 4, a consequence of our estimation strategy. The figure shows the actual maximum score and simulated maximum scores for $\lambda=0.25,0.5$ and 1 . Note how the lines move up as $\lambda$ rises (or correlation falls) so that the extent of overlap increases.

We pin down $\lambda$ using a simulation-based approach. The simulation algorithm works as follows: For a given vector $\lambda$, we obtain the vector $\boldsymbol{\delta}(\mathbf{q}, \lambda)$ and simulate the minimum and maximum cutoff scores, $\underline{c}_{j}$, and $\bar{c}_{j}$, for each school. Then we find the vector $\lambda$ that best matches the actual maximum and minimum cutoff scores.

Simulating the error terms in the nested logit model creates some difficulties: taking a draw from the GEV distribution with the standard Markov Chain Monte Carlo Method is computationally intensive. We use a method proposed by Cameron and Kim (2001) which takes a draw from the GEV distribution using a far less computationally intensive procedure. ${ }^{18}$

We draw $M(=100)$ sets of error terms $\varepsilon_{i j}$ for each student from the distribution function given in Eq. (1) by using the parameters, $\lambda$. For each of the $M$ sets of errors drawn, $\varepsilon_{k}=\left\langle\varepsilon_{i j}^{k}\right\rangle, k=1, . . M$, we allocate students to schools by using the placement rule. ${ }^{19}$ After drawing each set of errors we get a distribution of scores for students in each school. Let $g_{j}{ }^{k}$ be the set of scores in school $j$ in simulation $k$, ordered to be increasing ${ }^{20}$ :

\footnotetext{
18 This method is explained in Appendix A.1

${ }^{19}$ We focus on the highest scoring 50,000 students to reduce computational intensity. The score of the student whose rank is 50,000 is lower than the minimum cutoff score of 216 schools and lower than the maximum cutoff score of all 226 schools.

${ }^{20}$ In the method proposed by Cameron and Kim (2001), a change in $\lambda$ only affects the coefficients. This allows us to keep the random seeds drawn from the extreme value distribution over simulations and only change coefficients.
} 
Table 1

Nesting parameters: $\lambda$.

\begin{tabular}{|c|c|}
\hline Variable & Coefficient \\
\hline$\lambda_{l o c}$ & $\begin{array}{l}0.958 \\
(0.0001)\end{array}$ \\
\hline$\lambda_{\text {voc }}$ & $\begin{array}{l}0.986 \\
(0.0005)\end{array}$ \\
\hline$\lambda_{\text {ank }}$ & $\begin{array}{l}0.795 \\
(0.0007)\end{array}$ \\
\hline$\lambda_{i s t}$ & $\begin{array}{l}0.837 \\
(0.0016)\end{array}$ \\
\hline$\lambda_{i z m}$ & $\begin{array}{l}0.777 \\
(0.0004)\end{array}$ \\
\hline$\lambda_{\text {teach }}$ & $\begin{array}{l}0.999 \\
(0.0000)\end{array}$ \\
\hline$\lambda_{s c i}$ & $\begin{array}{l}0.897 \\
(0.0018)\end{array}$ \\
\hline
\end{tabular}

Note: Standard errors are reported in parentheses.

$$
g_{j}^{k}(\lambda)=\left\langle s_{j 1}^{k}(\lambda), s_{j 2}^{k}(\lambda), \ldots, s_{j q_{j}}^{k}(\lambda)\right\rangle
$$

After ordering scores in ascending order for each school $j$ and simulation $M$, we find the expected value of the score for each rank within each school across the $M$ simulations. The expected score of student with rank $r$ in school $j$ is thus:

$$
s_{j r}^{*}(\lambda)=\frac{1}{M} \sum_{k=1}^{M} s_{j r}^{k}(\lambda)
$$

$$
\begin{aligned}
& \text { Let } g_{j}^{*}(\lambda) \text { be } \\
& \qquad g_{j}^{*}(\lambda)=\left\langle s_{j 1}^{*}(\lambda), s_{j 2}^{*}(\lambda), \ldots, s_{j q_{j}}^{*}(\lambda)\right\rangle .
\end{aligned}
$$

We take the lowest and highest ranked mean simulated score in each school. We find the $\lambda$ that gives the least square distance between these simulated minimum and maximum cutoff scores and observed minimum and maximum cutoff scores. In effect, we are matching the maximum scores as the minimum scores are matched on average given our estimation procedure for obtaining $\delta$ :

$$
\hat{\lambda}=\arg \min _{\lambda} \frac{1}{N} \sum_{j}\left(s_{j q_{j}}^{*}(\lambda)-\bar{c}_{j}\right)^{2}+\frac{1}{N} \sum_{j}\left(s_{j 1}^{*}(\lambda)-\underline{c}_{j}\right)^{2}
$$

Table 1 shows the $\lambda$ values for each nest that minimize the distance between simulated and real maximum and minimum cutoff scores. As we mentioned before, $\lambda$ is a measure of dissimilarity in preferences within a nest. If $\lambda$ is small, students rank schools in the same nest according to their perceived quality $(\boldsymbol{\delta})$ so that students tend to agree on the ranking of schools. However as $\lambda$ gets bigger, students differ in their preferences and no such ranking exists as their tastes for schools differ.

The correlation in shocks is low for vocational, teacher and local schools, suggesting that preferences are more horizontal there. This makes sense as these schools do not tend to be vertically differentiated: students usually go to the nearest one. As a result, the overlap in the support of scores in these schools is large which drives the high estimate for $\lambda$. The correlation is highest in the İzmir, Ankara, and İstanbul Anatolian high school nests (as $\lambda$ is lowest). Note that the smaller the city, the higher the correlation in the city nest, as might be expected. In large cities, there may be enough schools so that students can choose the school that is most convenient without sacrificing much in quality. This would be picked up as greater horizontal differentiation, i.e., a higher $\lambda$. Science high schools are also more vertically differentiated than the others which again makes sense as they are the most elite of the schools. These findings suggest, quite reasonably, that students' preferences are vertical for selective Anatolian and Science high schools, but less so for less selective vocational, teacher and local schools. Moreover, the standard errors are low so that the estimates are tight. ${ }^{21}$

The real and simulated cutoff scores for $\lambda$ presented in Table 1 are given in Fig. 5 . As we can see simulated maximum scores track the real maximum cutoffs quite well. Note that the actual maximum score is more variable than that estimated one. Heterogeneity in preferences comes from the error term. In our data we have no information about individual students preferences such as the school's location relative to their own home. As a result the error term ends up having more noise in it. For example, a very good student may choose a less selective Anatolian School just because it is close to where he comes from. This would raise the maximum score there above what the model predicts. If we had better information on students, we expect that we could do better at matching the maximum score.

\footnotetext{
${ }^{21}$ The simulations were bootstrapped 13 times to get the standard errors.
} 


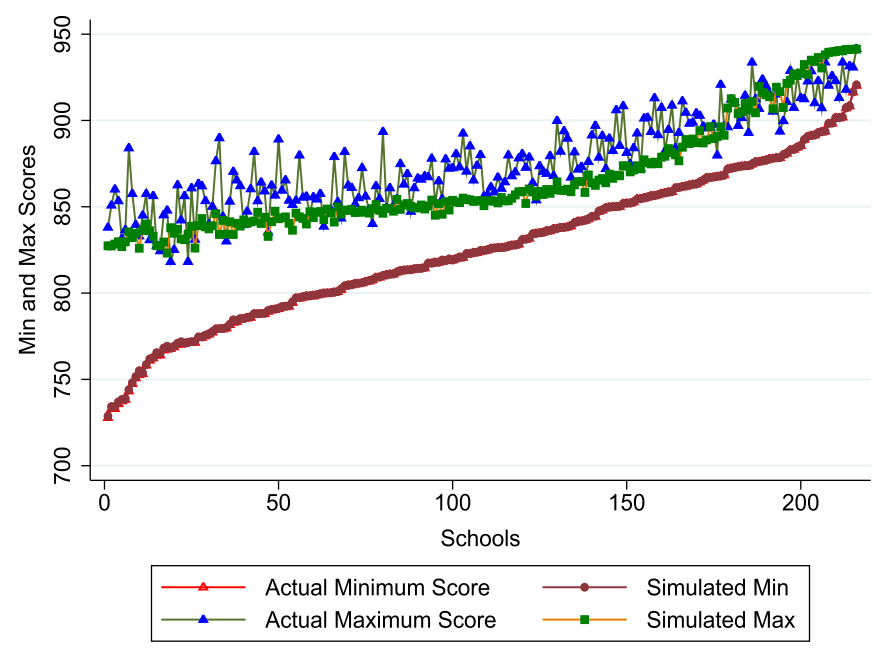

Fig. 5. Real and simulated cutoff scores.

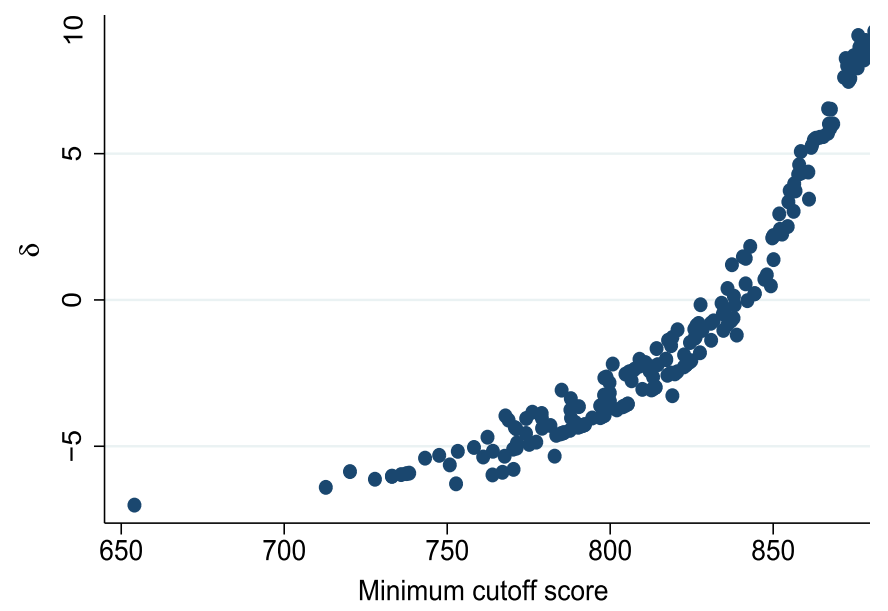

Fig. 6. Perceived valuation w.r.t. minimum cutoff score.

Fig. 6 depicts the relationship between the perceived valuation and the selectivity of schools. More selective schools clearly seem to be more valued. Close to the top of the score distribution a small increase in the score raises utility a lot while a similar increase at low scores has little effect. In the next step, we investigate the factors affecting the students' perceived valuations of the schools.

\subsection{What drives valuations?}

Once we pin down the $\lambda$ that gives the best match of the actual and the simulated cutoffs, we get $\hat{\boldsymbol{\delta}}$ (q, $\hat{\lambda}$ ). Returning to the definition of $\boldsymbol{\delta}$, the vector of mean valuations for schools,

$$
\widehat{\delta}=\boldsymbol{\beta} \mathbf{X}+\xi
$$

where $X$ is the observed characteristics of the school, and $\xi$ is the school specific component of mean valuations. $\xi$ is the unobserved, common across all agents, school specific preference shock. $X$ includes the school's success on the ÖSS the previous year, its age/ experience, type, education language, dormitory availability, whether it is located in a big city (Ankara, İstanbul, or İzmir), the number of seats, and the cutoff score of the school. Agents may value selectivity, i.e., a high cutoff score, for the associated bragging rights and/or because they use it as a signal for unobserved quality. The cutoff score is an equilibrium outcome and so endogenous by definition. The dummy for being a Science or Anatolian high school incorporates the possibility that such schools have a good reputation and this makes people value them. This could be for consumption purposes, perhaps for the bragging rights associated with going there.

The cutoff score is an equilibrium phenomenon. An increase in the valuation (though any of the channels that people seem to care about) will shift demand out and raise the cutoffs. An increase in the number of seats will both change the valuation (if agents 
care about the school size) and so shift demand and raise the cutoff. It will also directly affect supply so that the cutoff will fall. ${ }^{22}$

We allow valuations to depend on a number of factors, including the cutoff score itself. ${ }^{23}$ The equilibrium cutoff is then a fixed point: given the equilibrium cutoff, valuations generate the same cutoff in equilibrium. In Eq. (2) there is a valuation shock, $\xi$, which acts as the error term. There is thus an econometric issue associated with including the cutoff score as an explanatory variable. ${ }^{24}$ If $\xi$, the school specific valuation shock, is large and positive, then the cutoff score will be high as well, so that the cutoff will be correlated with $\xi$. This will bias the estimates of $\boldsymbol{\beta}$ obtained upward. This is the familiar endogeneity problem. To deal with this we need good instruments for the cutoff score. We partition $\mathbf{X}$ as $[\widetilde{\mathbf{X}}, \underline{\mathbf{c}}]$ so that

$$
\widehat{\boldsymbol{\delta}}=\widetilde{\boldsymbol{\beta}} \widetilde{X}+\gamma \underline{\mathbf{c}}+\boldsymbol{\xi}
$$

A good instrument is an exogenous variable that shifts the cutoff score, but does not affect a school's average valuation $\delta$ directly. The first variable that comes to mind that shifts the minimum cutoff score is the number of available seats in a school. However, the available number of seats may affect the valuation of the school directly. In addition, it may be a response to a high $\xi$ which makes it less than optimal. ${ }^{25}$ Fortunately, the model suggests which instruments to use for the minimum cutoff score. Next, we explain what these are and how we construct them, and then present our results. ${ }^{26}$

The model predicts that the number of available seats in schools worse than a given school has no effect on the demand for the school. However, the number of seats in better schools does affect demand: more seats in better schools are predicted to reduce the cutoff score of a school. This comes from the observation that the demand for a school comes from those who like it the most, from the alternatives that are open to them. Changing the cutoff in worse schools has no effect on the alternatives open to a student going to a better school, and hence, on their demand. In other words, if Podunk University offers more seats, there is no effect on the demand for Harvard since everyone choosing to go to Harvard had, and continues to have, Podunk in their choice set. But if Harvard offers more seats, it may well reduce the demand for Podunk University. It could be that someone chose Podunk because they could not get into Harvard. Once Harvard increases its seats and so reduces its own cutoff, Harvard may become feasible for such a student. As we use seats in other schools to instrument for a school's cutoff we need not worry about any correlation with $\xi$.

To construct the instrumental variable, we need a ranking of schools free of $\xi$. We will use the schools' success on the verbal and quantitative part of the ÖSS in the previous year to rank schools. ${ }^{27}$ We construct our instrumental variable as follows:

1. For each school, we find the schools that have better average test scores in both dimensions, verbal and quantitative.

2. We find the total number of seats in all of the schools found in step 1 . The available number of seats in the school itself is not included.

The second set of instruments we use is constructed using a different insight. A large positive draw of $\xi$, the school specific demand shock, would raise demand for the school and so raise both the minimum score and the maximum score. As a result, the residual from the regression of the minimum cutoff score on a flexible form of the maximum score will be correlated with the minimum cutoff, but orthogonal to the school specific demand shock, $\xi$. This makes it a good instrument. ${ }^{28}$ We thus use the residual of the minimum score on a polynomial function of maximum score as an instrument for the minimum cutoff score ${ }^{29}$ :

$$
\underline{c}=\lambda_{0}+\lambda_{1} \bar{c}+\lambda_{2} \bar{c}^{2}+\nu
$$

Table 2 shows our first stage estimation:

$$
\underline{c}=\eta \widetilde{X}+\kappa_{1} * \text { Seats in better schools }+\kappa_{2} * \hat{\nu}+\varepsilon
$$

Note that the number of seats in better schools has a negative coefficient: more seats in better schools reduce the school's own cutoff as expected. The second instrumental variable, the residual from the regression of minimum cutoff on a polynomial function of maximum score, has a positive coefficient as expected since the minimum score would be increased by a positive shock as captured by a positive residual.

Finally, according to the model, the number of seats in worse schools should have no effect on the school's own cutoff. Table A8 presented in Appendix A.3 shows the first stage estimation after adding as an additional instrument the number of seats in lower scoring schools. As expected, this additional instrument is not significant. We also test for the exogeneity of the cutoff score using a Hausman test and reject the hypothesis with $p$-value equal to 0 . Our model is overidentified. According to the results of heteroskedasticity-robust score test (Wooldridge, 1995), we cannot reject this hypothesis with $p$-value 0.17.

\footnotetext{
22 The net effect will be negative if the equilibrium is stable.

23 This is like putting in the price into the utility function: people get utility from the price being higher in a Veblenesque manner.

24 The same criticism might be thought to apply to variables like the school's average score in (parts of) the university entrance exam. However, it is far from clear why this would happen. Even if class quality today rose with the cutoff, this would only affect university entrance exam results with a $3 y e a r$ delay.

25 This is less of a concern in Turkey, where the number of seats is usually equal to the size of the graduating class as the overall school size is set by the central authority and can be thought of as exogenous.

26 An exogenous change in the cutoff score could occur if it was misreported by accident and last years cutoffs affected this years valuations.

27 Of course, there could still be a problem if demand shocks when the students in the previous year were admitted was strongly serially correlated with today's demand shock. As long as the correlation between the demand shock today and at the time the students in the previous year were admitted are small, our instrument is valid.

${ }^{28}$ One might ask what could affect the maximum score and not the minimum score. The score distribution around the cutoff score of a school does not affect its maximum score but it affects its minimum cutoff score.

${ }^{29}$ Hoxby (2000) uses an instrumental variable constructed with similar logic.
} 
Table 2

First stage estimation.

\begin{tabular}{|c|c|}
\hline Variable & Coefficients \\
\hline Number of available seats & $\begin{array}{l}0.087 \\
(0.061)\end{array}$ \\
\hline Average quantitative score in 2000 ÖSS & $\begin{array}{l}1.240 \\
(0.531)\end{array}$ \\
\hline Average verbal score in 2000 ÖSS & $\begin{array}{l}1.167 \\
(0.765)\end{array}$ \\
\hline Age & $\begin{array}{l}0.267 \\
(0.316)\end{array}$ \\
\hline Science high school & $\begin{array}{l}56.99^{* \ldots * *} \\
(14.890)\end{array}$ \\
\hline Teacher high school & $\begin{array}{l}45.37^{*} \\
(16.260)\end{array}$ \\
\hline Anatolian high school in İstanbul & $\begin{array}{l}24.090 \\
(19.870)\end{array}$ \\
\hline Anatolian high school in İzmir & $\begin{array}{l}13.460 \\
(20.850)\end{array}$ \\
\hline Education language - English & $\begin{array}{l}11.410 \\
(11.160)\end{array}$ \\
\hline Education language - German & $\begin{array}{l}-3.628 \\
(11.810)\end{array}$ \\
\hline Dormitory availability & $\begin{array}{l}13.140 \\
(6.895)\end{array}$ \\
\hline Ankara & $\begin{array}{l}26.46^{*} \\
(12.690)\end{array}$ \\
\hline İstanbul & $\begin{array}{l}23.780 \\
(14.750)\end{array}$ \\
\hline İzmir & $\begin{array}{l}30.93^{*} \\
(15.110)\end{array}$ \\
\hline Seats in better schools & $\begin{array}{l}-0.00358 \\
(0.002)\end{array}$ \\
\hline Residual from min regression & $\begin{array}{l}0.740^{* * *} \\
(0.087)\end{array}$ \\
\hline Constant & $\begin{array}{l}708.2^{* * * * *} \\
(35.050)\end{array}$ \\
\hline$F$-stat (Excluded variables) & 41.512 \\
\hline$R^{2}$ & 0.802 \\
\hline$N$ & 161 \\
\hline
\end{tabular}

Note: Standard errors are reported in parentheses.

* Significance at the 0.90 level.

** Significance at the 0.95 level.

**** Significance at the 0.99 level.

The first column of Table 3 shows our baseline estimates, where we regress average valuation on the exogenous variables and do not include the minimum cutoff score of a school. This column suggests that past performance on the university entrance exam (ÖSS scores) and school type drive preferences. The second column of Table 3 shows the results of the regression of the average valuation on the exogenous variables and the school's cutoff score. The coefficient on the minimum score is positive and highly significant suggesting that a more selective school is highly valued. The significance of past scores on the university entrance exam are less significant, as would be expected given that the cutoff is positively correlated with the past performance of a school so that including it picks up some of this variation. However, as explained above, cutoffs are not exogenous. As cutoffs are high when the school preference shocks are high, cutoffs are positively correlated with the error term which imparts an upward bias to the coefficient. The third and fourth columns show the results when we instrument for cutoffs. The third column reports the 2SLS estimates, and the fourth column reports the limited information maximum likelihood (LIML) estimates. The latter has better small sample properties. It is reassuring that the estimates from both methods are very similar. In addition, note that after instrumenting for the cutoff score, the coefficient on it falls (as expected) but remains positive and significant. Past performance on the university entrance exam becomes more significant suggesting that, conditional on the cutoff, a school's performance on the university entrance exam is an important determinant of its valuation. Thus, students do look at how well students graduating, or the output of a school, in forming their valuation of a school. These results are consistent with the findings of Burgess et al. (2009) and Hastings et al. (2008) who reach a similar conclusion using data from the Millennium Cohort Study in the UK, and school choice data from the CharlotteMecklenburg School District, respectively. ${ }^{30}$

\footnotetext{
${ }^{30}$ The significance level of the "seats in better schools" instrument is lower than the "residual from min regression" instrument. One might wonder whether our results are sensitive to estimating the model just by using the "residual from min regression" instrument. Tables A9 and A10 show that neither the coefficient on the
} 
Table 3

School choice: estimation results.

\begin{tabular}{|c|c|c|c|c|}
\hline Variable & (OLS) & (OLS) & $(2 \mathrm{SLS})$ & (LIML) \\
\hline \multirow[t]{2}{*}{ Number of available seats } & 0.005 & $0.00842^{*}$ & 0.007 & 0.007 \\
\hline & $(0.007)$ & $(0.004)$ & $(0.004)$ & $(0.004)$ \\
\hline \multirow[t]{2}{*}{ Average quantitative score in 2000 ÖSS } & $0.218^{* * * *}$ & $0.0680^{*}$ & $0.116^{n / x}$ & $0.117^{* * *}$ \\
\hline & $(0.053)$ & $(0.033)$ & $(0.036)$ & $(0.036)$ \\
\hline \multirow[t]{2}{*}{ Average verbal score in 2000 ÖSS } & $0.306^{* * * *}$ & $0.0865^{*}$ & $0.157^{* \text { *** }}$ & $0.159^{* * * *}$ \\
\hline & $(0.053)$ & $(0.038)$ & $(0.039)$ & $(0.040)$ \\
\hline \multirow[t]{2}{*}{ Age } & 0.026 & 0.032 & 0.030 & 0.030 \\
\hline & $(0.062)$ & $(0.031)$ & $(0.040)$ & $(0.040)$ \\
\hline \multirow[t]{2}{*}{ Science high school } & $8.422^{* * * *}$ & $3.237^{* * * *}$ & $4.892^{* * * *}$ & $4.936^{* * * *}$ \\
\hline & (1.764) & $(0.765)$ & (1.034) & (1.047) \\
\hline \multirow[t]{2}{*}{ Teacher high school } & $4.039^{*}$ & 0.867 & 1.880 & 1.907 \\
\hline & (1.931) & $(0.763)$ & (1.063) & (1.075) \\
\hline \multirow[t]{2}{*}{ Anatolian high school in İstanbul } & 1.928 & -0.544 & 0.245 & 0.267 \\
\hline & (2.152) & $(0.728)$ & $(1.156)$ & (1.169) \\
\hline \multirow[t]{2}{*}{ Anatolian high school in İzmir } & 1.715 & 0.392 & 0.814 & 0.826 \\
\hline & $(2.280)$ & $(0.679)$ & $(1.036)$ & (1.050) \\
\hline \multirow{2}{*}{ Education language - English } & 2.671 & -0.028 & 0.834 & 0.857 \\
\hline & $(2.192)$ & (1.118) & $(1.418)$ & (1.429) \\
\hline \multirow[t]{2}{*}{ Education language - German } & 1.198 & 0.330 & 0.607 & 0.615 \\
\hline & (2.254) & (1.175) & (1.458) & $(1.467)$ \\
\hline \multirow[t]{2}{*}{ Dormitory availability } & 1.617 & 0.500 & 0.856 & 0.866 \\
\hline & $(0.893)$ & $(0.455)$ & $(0.555)$ & $(0.558)$ \\
\hline \multirow[t]{2}{*}{ Ankara } & $4.235^{* * *}$ & 0.733 & $1.851^{*}$ & $1.881^{*}$ \\
\hline & (1.494) & $(0.485)$ & $(0.784)$ & $(0.795)$ \\
\hline \multirow[t]{2}{*}{ İstanbul } & $4.485^{* * * *}$ & $1.687^{* \text { *. }}$ & $2.580^{* * *}$ & $2.604^{* * *}$ \\
\hline & (1.297) & $(0.522)$ & $(0.771)$ & $(0.779)$ \\
\hline \multirow[t]{2}{*}{ İzmir } & 3.746 & 0.608 & $1.610^{* * *}$ & $1.637^{* *}$ \\
\hline & (1.449) & $(0.381)$ & $(0.580)$ & $(0.591)$ \\
\hline \multirow[t]{2}{*}{ Minimum cutoff score } & & $0.0846^{* * * *}$ & $0.0576^{* * * *}$ & $0.0569^{* * * * *}$ \\
\hline & & $(0.006)$ & $(0.007)$ & $(0.008)$ \\
\hline \multirow[t]{2}{*}{ Constant } & $-22.95^{* * * *}$ & $-76.18^{* * * * *}$ & $-59.19^{* \text { *** }}$ & $-58.73^{* * * *}$ \\
\hline & $(3.121)$ & $(4.363)$ & $(4.596)$ & $(4.654)$ \\
\hline$R^{2}$ & 0.807 & 0.942 & 0.928 & 0.927 \\
\hline$N$ & 161 & 161 & 161 & 161 \\
\hline
\end{tabular}

Note: Corrected standard errors are reported in parentheses.

* Significance at the 0.90 level.

** Significance at the 0.95 level.

**** Significance at the 0.99 level.

Science high schools and schools in İstanbul, Ankara, and İzmir are also valued beyond what they would be based on their selectivity alone. As mentioned before, Science high schools are very prestigious. It could be that attending such schools gives one contacts in the future as well as a consumption value in the present. MacLeod and Urquiola (2009) show that a school's reputation can affect wages as the identity of the school attended gives information about a student's ability. This could also rationalize the high valuation placed on Science high schools. It could also be that the high valuation of Science high schools comes from the students' use of school type as a proxy for school quality. In the next section we look at the value-added of each Science high school by estimating the effect or the value added of the high school on their students' performance on the university entrance exam.

\section{Value-added by high schools}

In the previous section, we estimated the preference parameters and simulated the high school entrance exam scores for students in each school. We allocated students to schools on the basis of the estimated preference parameters and the overall score distribution using simulations. In this section, we estimate the value-added by a school in terms of their students' academic performance. Here we are limited by the data. We do not have a panel, so we cannot match the score the student obtained on the high school entrance exam to what he obtained on the university entrance exam. Rather, we infer the effects of schools on student performance by comparing the mean high school entrance exam (OKS) score to the mean university entrance exam (ÖSS) scores for each school. We have many years for the latter, but only one year for the former. We estimate the average value added per school by running a regression of the difference in the (standardized) mean score of a school in the university entrance exam and in the high

(footnote continued)

"residual from min regression" in the first stage nor the coefficient on the minimum score in the second stage change by much. 
school entrance exam on a school dummy and an error term. ${ }^{31}$ We discover patterns that suggest that better schools are resting on their laurels, while the schools at the bottom are scrambling to improve. However, we argue that this could be reflecting mean reversion. By using simulation based methods as well as information on each student in a single school, we estimate the average value-added by a school while controlling for mean reversion.

\subsection{The approach}

In this section, we look only at Science high school students because their program is homogeneous since all students follow the science track. Students in these schools will be placed on the basis of a score that gives greater weight to the science and math part of the exam, the ÖSS-SAY score, which is what we use as the performance measure on the university entrance exam. We standardize scores by using the mean and the standard deviation of scores within all Science high schools.

We assume that student $i$ 's high school entrance exam score depends on his ability, $\alpha_{i}$, and his i.i.d. mean zero shock, $\varepsilon_{i}^{h s}$, and that his university entrance exam score depends on his ability, the value-added of the school he attended, and the shock to the university entrance exam score, $\varepsilon_{i j}{ }^{c} . \varepsilon_{i j}^{c}=u_{j}+v_{i}^{c}$ where $u_{j}$ and $v_{i}^{c}$ which are the school specific and individual specific components of the university entrance exam score shock and are independently distributed, mean zero error terms. Thus

$$
s_{i}^{h s}=\alpha_{i}+\varepsilon_{i}^{h s}
$$

and

$$
s_{i j}^{c}=\alpha_{i}+\gamma_{j}+\underbrace{\varepsilon_{i j}^{c}}_{u_{j}+v_{i}^{c}}
$$

where $j$ indexes schools and $\gamma_{j}$ is the school value-added. Assume that $\alpha_{i}, \gamma_{j}, u_{j}, v_{i}^{c}$ and $\varepsilon_{i}^{h s}$ are independent of each other. The school level common shock, $u_{j}$, is a shock affecting the performance of all students in the school. $\varepsilon_{i}^{h s}$ and $v_{i}^{c}$ can be thought as idiosyncratic shocks such as air pollution (Ebenstein et al., 2016) or the noise level near where students take the exam (students take both exams in schools that they are assigned randomly in a city that they prefer) that affect performance, but are uncorrelated with other observables. We do not observe the individual students' scores, but only the school level average scores for the university entrance exam. Thus, aggregating to the school level in the model above, we get the mean scores in the OKS and ÖSS from school $j$ :

$$
E\left(s_{i}^{h s} \mid j\right)=E\left(\alpha_{i} \mid j\right)+E\left(\varepsilon_{i}^{h s} \mid j\right)
$$

and

$$
E\left(s_{i j}^{c} \mid j, t\right)=E\left(\alpha_{i} \mid j, t\right)+\gamma_{j, t}+E\left(\varepsilon_{i j}^{c} \mid j, t\right)
$$

The $t$ is the time index as we have more than a single year's data on the university entrance exam. Under the following assumptions, we can get a consistent estimate of the school value-added, $\gamma_{j, t}$, by using the data on the performance of the schools over time.

Assumption 1. $E\left(\varepsilon_{i}^{h s} \mid j\right)=0$.

Assumption 1 is a heroic one and is unlikely to hold in the data we have. Students with better scores, and hence with better shocks to their scores on the high school entrance exam, get into a better school while those with worse ones do not. As a result, it is expected that the mean scores of students in the best (worst) high schools will look like they have fallen (risen) in the university entrance exam even if there is actually no value-added by any school. This is the familiar mean reversion issue. All we are saying here is that if Assumption 1 holds, then we can easily estimate value added. If it is grossly untrue, then our estimates will be biased due to mean reversion and we will need to correct for this.

Assumption 2. $E\left(\alpha_{i} \mid j, t\right)=E\left(\alpha_{i} \mid j\right) \forall t$.

Assumption 2 states that students placed in a school have the same ability on average over time. This is a reasonable assumption in the Turkish system. The cutoff scores are fairly stable as the educational environment in Turkey has been unchanged over the last few decades. In Appendix A.2 we present evidence on the stability of cutoff scores.

Assumption 3. $\gamma_{j, t}=\gamma_{j} \forall t$.

Assumption 3 says that school value-added is time-invariant. Assumptions 1-3 imply that the variation in the performance of a school comes from the shock, $u_{j t}$, received by that school in that year.

Under these assumptions the average performance of students in school $j$ at time $t$ can be written as

$$
E\left(s_{i j}^{c} \mid j, t\right)=E\left(s_{i}^{h s} \mid j\right)+\gamma_{j}+E\left(u_{j}+v_{i}^{c} \mid j, t\right) E\left(s_{i j}^{c} \mid j, t\right)-E\left(s_{i}^{h s} \mid j\right)=\gamma_{j}+E\left(u_{j} \mid j, t\right)
$$

To account for the correlation in the shocks received by a school over time, we cluster standard errors at the school level.

Value added modeling has become a key tool in the attempt to evaluate teachers and institutions, especially in the US, see Koedel et al. (2015) for a useful survey of recent work. Two papers stand out in this literature. Chetty et al. (2014a) use value added modeling to monetize the gains that would occur from improving teachers using Internal Revenue Service (tax) data. Their work

\footnotetext{
${ }^{31}$ See Todd and Wolpin (2003) for identifying assumptions and data requirements for different value-added estimators.
} 
suggests that these gains are large: replacing a teacher in the bottom $5 \%$ in terms of value added with an average one would raise the present discounted value the earnings of all students in the class by $\$ 250,000$. However, Rothstein (2015) criticizes these estimates as being biased due to unobserved sorting. His argument is elegant and devastating. He shows that after adding the usual controls, current student test score growth is correlated with future teacher value added, suggesting that student assignments to teachers are not random. However, Chetty et al. (2015) argue that future value added is generated from past student scores leading to a mechanical correlation noted by Rothstein (2015). ${ }^{32}$

Deming (2014) also points out that only controlling for prior test scores may not be enough to control for sorting across schools so that value-added estimates will be biased. In our framework, if students with better (worse) unobserved characteristics sorted into more (less) selective schools our value-added estimates would be upward biased for more selective schools and downward biased for less selective schools. There is also considerable controversy over the persistence of teacher value added and on the viability of using such measures to incentivize students. After all, if teachers are judged by a given yardstick, they will naturally direct their efforts to look good according to the yardstick (perhaps by teaching to the test rather than encouraging understanding of the material) with long run costs. ${ }^{33}$

\subsection{Results}

Before we present our results, we examine the patterns in the data on the schools' average performance on the university and high school entrance exams, to understand the effect of noise on the average performance of schools. The patterns seem to be driven by ability sorting, value added, and mean reversion. We normalize the average ÖSS score and the average OKS scores so that they have mean zero and variance of unity.

Looking at the patterns in the data we see that there seems to be a role for ability in the sorting between schools. If ability did not affect the scores on the high school and the university entrance exams, then allocation of students to schools would be independent of ability. In that case, the correlation between the (normalized)average ÖSS score and the average OKS score would be zero if there is no value-added by schools. If there was value added by schools, and this mattered to students, then the high value added schools should be harder to get into and sorting by ability should occur. The correlation and rank correlation of these mean OKS and the mean ÖSS scores are strongly positive as in Table 4 and 5 suggesting some sorting by ability.

If there was sorting on the basis of ability and/or preferences, no value-added by any school, and no randomness in OKS scores, we would expect the normalized OKS and ÖSS scores to lie along the 45 degree line. When we plot normalized OKS and ÖSS scores as in Fig. 7, the fitted line is flatter than the 45 degree line, which is in red. This should not be taken to mean that more selective schools have negative value added as this could arise from mean reversion if there was randomness in the OKS scores.

The less the randomness in the OKS score relative to the variation in ability, the more informative is the high school entrance exam score and the lower the extent of mean reversion bias. If we knew, or could assume something about the variance in the OKS score, we might be able to pin down the value-added by a school.

Fig. 8 presents the same data in a slightly different way. It orders schools on the basis of their cutoffs, not the average score, with School 1 being the least selective one. Thus, the schools are ordered from "worst" to "best". Each school's score on the university entrance exam from 2002 to 2007 as well as the high school entrance exam score in 2001 is plotted. The high schools whose normalized ÖSS scores are significantly higher than their OKS ones, i.e., those with positive "value-added" are highlighted in blue, while those with significantly negative "value-added" are highlighted in red. No highlight means the estimated value-added is not significantly different from zero. Note that the value added here is contaminated by mean reversion.

The least selective schools seem to add value on average and the most selective ones seem to reduce it, although School 4, one of the worst schools, reduces value. As discussed above, this broad pattern could be just a reflection of mean reversion. In the next section, by using auxiliary student level data from a school, we estimate the magnitude of the mean reversion bias and correct for it.

\subsection{Mean reversion bias}

In the previous section we noted that the mean difference in school performance in the OKS and ÖSS exams captures both mean reversion and value-added. In this section, by using auxiliary student-level data we were able to obtain for only one school, we develop a way to correct for the bias due to mean reversion. This auxiliary data contains each student's name, their high school score and their college entrance exam score. This school (which is not a Science high school, but is an Anatolian exam school) has roughly the same cutoff score as the one with rank 16 in Table $4 .{ }^{34}$

As in the previous section, we normalize scores within this Anatolian exam school so that the mean score is zero and its standard deviation is 1 on both exams. If the value-added by a school is constant across students ${ }^{35}$ then student $i$ 's high school and university entrance exam scores are given by $^{36}$

\footnotetext{
32 There is an ongoing debate on this issue, see Chetty et al. (2014a,b, 2015), Rothstein (2015), and Bacher-Hicks et al. (2014).

33 This is well understood in the principal agent literature as the optimal contract may be to not provide high powered incentives for easily measured outcomes. For example, tying remuneration of CEOs to stock prices may cause them to direct their efforts to short term projects rather than long term ones that build value.

34 This is the only school that posted incoming students OKS scores as well as their OSS scores when they graduated on its website.

35 This is a strong assumption. A school may add positive value to some students and not to others as in Duflo et al. (2011). However, if this assumption fails to hold, we cannot account for mean reversion in our data.

${ }^{36}$ As the scores are normalized within the school, value-added is wiped out.
} 
Table 4

Correlation of the mean OKS score with the mean ÖSS scores.

\begin{tabular}{|c|c|c|c|c|c|c|c|}
\hline Mean score & OKS & ÖSS 2002 & ÖSS 2003 & ÖSS 2004 & ÖSS 2005 & ÖSS 2006 & ÖSS 2007 \\
\hline OKS & 1 & & & & & & \\
\hline ÖSS 2002 & 0.6667 & 1 & & & & & \\
\hline ÖSS 2003 & 0.7239 & 0.8474 & 1 & & & & \\
\hline ÖSS 2004 & 0.7242 & 0.8816 & 0.8949 & 1 & & & \\
\hline ÖSS 2005 & 0.7146 & 0.6666 & 0.7522 & 0.7989 & 1 & & \\
\hline ÖSS 2006 & 0.838 & 0.7761 & 0.8231 & 0.863 & 0.8027 & 1 & \\
\hline ÖSS 2007 & 0.811 & 0.7902 & 0.8807 & 0.8851 & 0.7893 & 0.8664 & 1 \\
\hline
\end{tabular}

Table 5

Correlation of the rank of the mean OKS and the mean ÖsS scores.

\begin{tabular}{llllllc}
\hline Rank of mean score & OKS & ÖSS 2002 & ÖSS 2003 & ÖSS 2004 & ÖSS 2005 & ÖSS 2006 \\
\hline OKS & 1 & & & & & \\
ÖSS 2002 & 0.8341 & 1 & & & & \\
ÖSS 2003 & 0.8191 & 0.7988 & 1 & & & \\
ÖSS 2004 & 0.8347 & 0.8228 & 0.8533 & 1 & 1 & 0.8013 \\
ÖSS 2005 & 0.7438 & 0.6365 & 0.7479 & 0.8927 & 0.7968 & 1 \\
ÖSS 2006 & 0.8758 & 0.8171 & 0.8971 & 0.8754 & 0.8825 \\
ÖSS 2007 & 0.851 & 0.7983 & 0.8489 & & & 1 \\
\hline
\end{tabular}

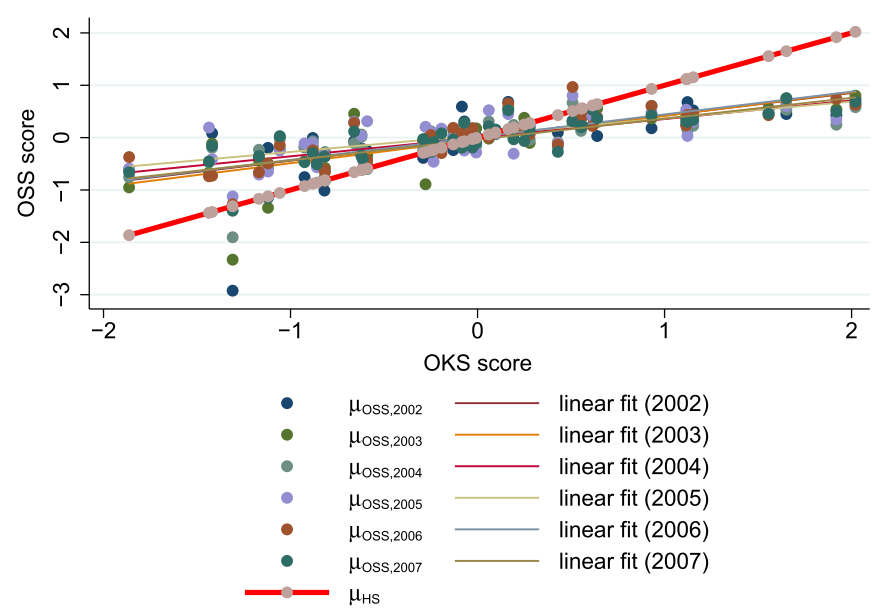

Fig. 7. Average ÖSS score by average OKS score. (For interpretation of the references to color in this figure, the reader is referred to the web version of this paper.)

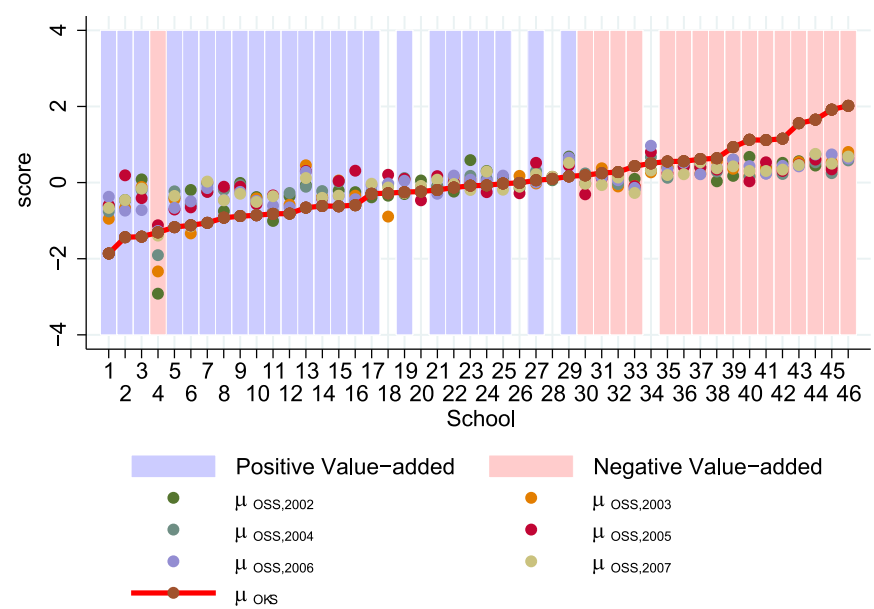

Fig. 8. Average OKS and ÖSS scores. (For interpretation of the references to color in this figure, the reader is referred to the web version of this paper.) 
Table 6

"Regression" coefficient: $\rho$.

\begin{tabular}{l}
\hline$\rho$ \\
\hline$-0.663^{* * * *}$ \\
$(0.0559)$
\end{tabular}

*** Significance at the 0.99 level.

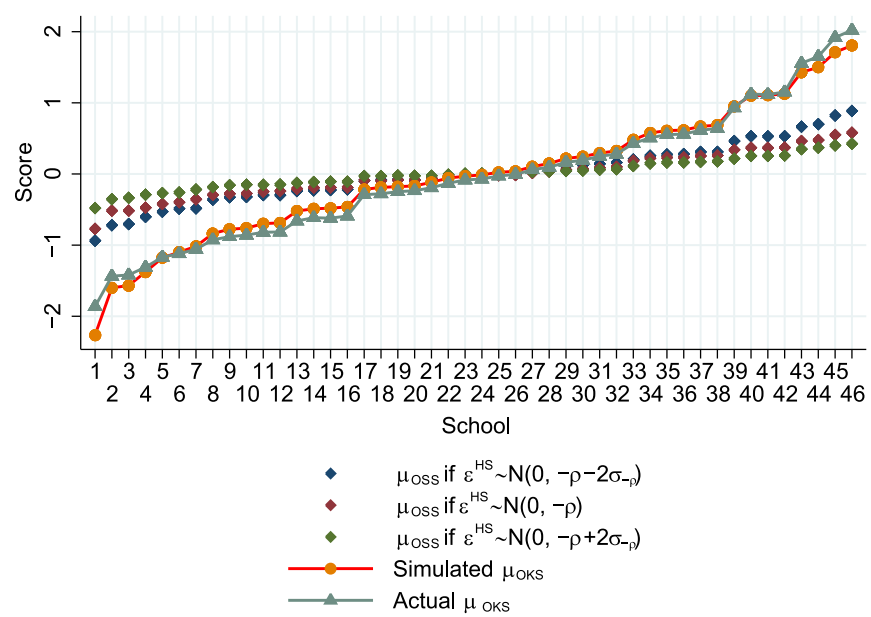

Fig. 9. Mean reversion bias: $\varepsilon^{h s} \sim N(0,-\widehat{\rho}), \varepsilon^{h s} \sim N\left(0,-\widehat{\rho} \pm 2 \sigma_{-\widehat{\rho}}\right)$. (For interpretation of the references to color in this figure, the reader is referred to the web version of this paper.)

$$
s_{i}^{h s}=\alpha_{i}+\varepsilon_{i}^{h s} s_{i}^{c}=\alpha_{i}+v_{i}^{c}
$$

where $\alpha_{i}$ is the ability of student $i$. We assume that $\alpha_{i}, v_{i}^{c}$ and $\varepsilon_{i}^{h s}$ are independent of each other. Students' scores on the high school entrance exam and university entrance exam differ from each other only in terms of the shocks received.

We used the approach introduced in Chay et al. (2005) to understand if there is mean reversion in the data. ${ }^{37}$ We look at the "regression" coefficient relating the score difference between high school and university entrance exam scores to high school entrance exam scores:

$$
s_{i}^{c}-s_{i}^{h s}=\rho s_{i}^{h s}+\omega_{i} \hat{\rho}=\frac{\operatorname{Cov}\left(s_{i}^{c}-s_{i}^{h s}, s_{i}^{h s}\right)}{\operatorname{Var}\left(s_{i}^{h s}\right)}=\frac{\operatorname{Cov}\left(s_{i}^{c}, s_{i}^{h s}\right)}{\operatorname{Var}\left(s_{i}^{h s}\right)}-1=\frac{\sigma_{\alpha}^{2}}{\sigma_{\alpha}^{2}+\sigma_{\varepsilon h s}^{2}}-1=\frac{-\sigma_{\varepsilon_{h s}}^{2}}{\sigma_{\alpha}^{2}+\sigma_{\varepsilon_{h s}}^{2}}
$$

If there is no mean reversion, $\hat{\rho}$ is zero. To build intuition, consider two extreme cases that show how $\hat{\rho}$ is related to mean reversion. Firstly, if we assume that high school entrance exam scores depend only on students' abilities and there is no noise, then $\sigma_{\varepsilon_{h s}}^{2}=0$ so $\hat{\rho}=0$. In this case, we do not expect to see mean reversion bias since there is no randomness in the high school entrance exam scores. Secondly, if we assume that high school entrance exam scores are just noise, $s_{i}^{h s}=\varepsilon_{i}^{h s}$, then ability does not affect score variation, which results in $\hat{\rho}$ being equal to -1 . In this case, the mean reversion bias is at its highest level. Therefore, $\hat{\rho}$ reflects the extent to which mean reversion creates a problem.

We observe students' scores on the high school and university entrance exams, so we can get an estimate of $\rho$.

Table 6 shows the estimate of $\rho$. As a result of our normalization process the variance of each of the scores is unity. As ability and shocks are orthogonal, $\sigma_{\alpha}^{2}+\sigma_{\varepsilon_{h s}}^{2}=1$. So we can recover the variance of the error distribution and the variance of the ability distribution from our estimate of $\rho$ :

$$
\sigma_{\varepsilon_{h s}}^{2}=-\hat{\rho} \sigma_{\alpha}^{2}=1+\widehat{\rho}
$$

The estimate of $\rho$ is quite large in absolute terms: noise accounts for $66 \%$ of the variance in the OKS score.

In our system, the allocation rule of students to schools is known and in the previous section, we estimated students' preferences over high schools. We can recover the average ability and shock received by students in each school by making a parametric assumption on the distribution of ability and noise on the high school entrance exam. We will assume that the ability has a normal distribution with the mean equal to zero and the variance equal to $(1+\hat{\rho})$. Similarly the distribution of the error term, $\varepsilon_{i}{ }^{h s}$, is normal with mean equal to zero and variance $-\hat{\rho}$. Under these assumptions, we generate high school entrance exam scores and allocate

\footnotetext{
37 Chay et al. (2005) use across-school variation to identify signal to noise ratio, while we use across-student variation to do the same.
} 


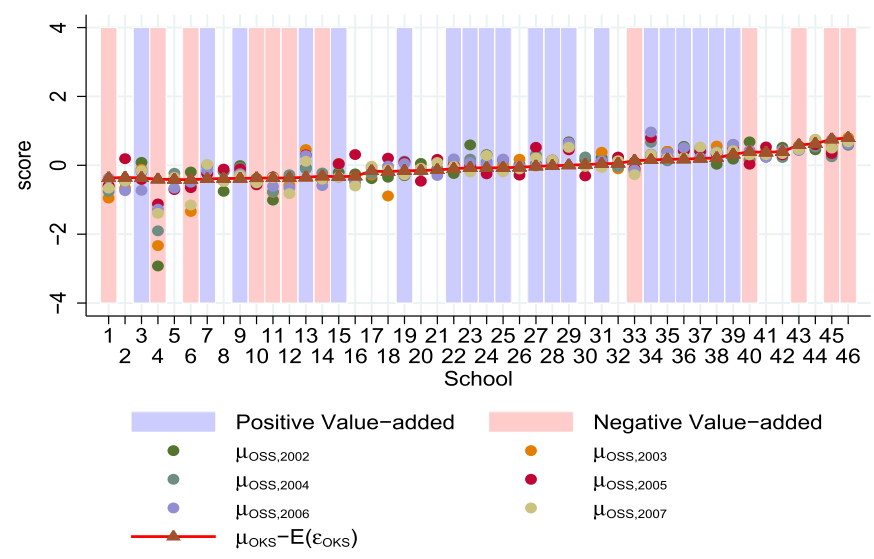

Fig. 10. Value-added: $\varepsilon^{h s} \sim N(0,-\widehat{\rho})$.

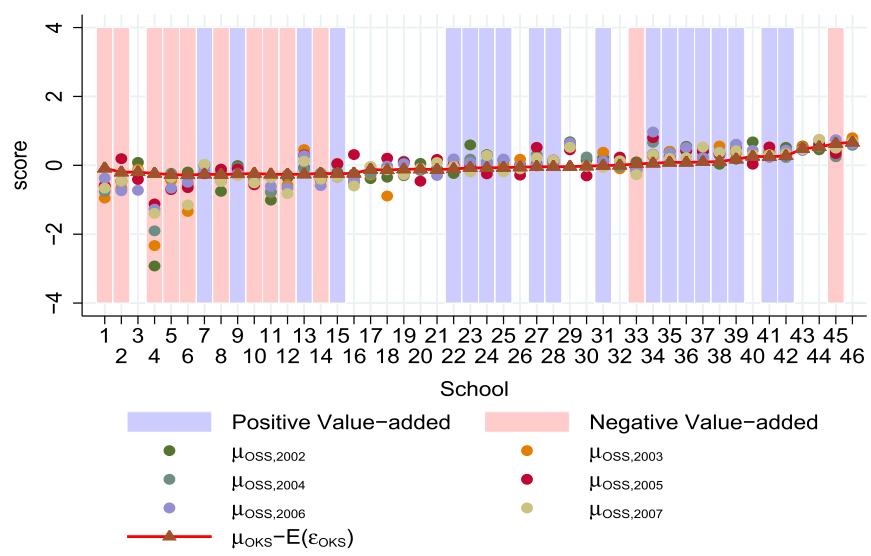

Fig. 11. Value-added: $\varepsilon^{h s} \sim N\left(0,-\hat{\rho}+2 \sigma_{-\widehat{\rho}}\right)$.

students to schools based on the estimated preferences. This gives the orange line (connecting the dots) in Fig. 9. We also present the mean scores on university entrance exams for this simulated allocation of students to schools when there isno value-added for different levels of variance in $\varepsilon_{i}^{h s}$, i.e., $\sigma_{\varepsilon_{h s}}^{2}$. The middle curve corresponds to the university entrance exam score with $\sigma_{\varepsilon_{h s}}^{2}=-\widehat{\rho}$. The ones above and below it correspond to the simulations where $\sigma_{\varepsilon_{h s}}^{2}$ is set at the $95 \%$ bands. In addition, we present the actual mean scores on the high school entrance exam to see if the simulated mean scores deviate from the actual ones. It is comforting to see that they look remarkably similar. They differ slightly for the most and least selective schools.

It is worth noting that preferences also affect the extent of mean reversion bias: the more vertical the preferences, the more the bias. With purely horizontal preferences, students who get lucky in their high school entrance exam performance are less likely to end up in the more selective schools reducing the extent of mean reversion bias.

Now we adjust for the mean reversion bias in our estimates by adding $E\left(\varepsilon_{i}^{h s} \mid j\right)$ to our estimates of value added to correct for mean reversion. In the figures, we also depict $\mu_{O K S}-E\left(\varepsilon_{O K S}\right)$ which is the mean high school entrance exam score adjusted for the mean reversion bias which rises far less slowly than the unadjusted one. Fig. 10 shows the schools' value-added estimates when we correct for the mean reversion bias. There is no particular pattern in value-added estimates according to selectivity. The most selective schools do not seem to have a positive effect on their students' test scores. However, it is also clear that some schools, such as schools 13, 29 and 35, improve their students scores, while others have negative value-added, such as schools 4, 11, 33 and 45. Figs. 11 and 12 do the same thing but allow for higher and lower levels of variance in $\varepsilon_{i}{ }^{h s}$, respectively, as defined by the confidence intervals above. As can be seen, with higher variance, there is more mean reversion to correct for so that more schools on the right add value and more on the left reduce value. With lower variance, we get the opposite happening. As our estimate of $\rho$ comes from only one school, it may not reflect that in science schools. If our estimate of $\rho$ is too high, we will overcorrect for mean reversion and thereby underestimate the value-added of schools at the top of the ranking and overestimate the value added of the schools at the bottom of the ranking.

Finally, we relate our value-added estimate to the valuations of the schools. ${ }^{38}$ Table 7 looks at what drives valuations for these Science high schools. We use a standardized regression here as we want to understand what seems to matter more. ${ }^{39}$ The results in

\footnotetext{
${ }^{38}$ In this section, as opposed to the results in Table 3, we focus only on Science high schools.

${ }^{39}$ Table A11 presents non-standardized regression results.
} 


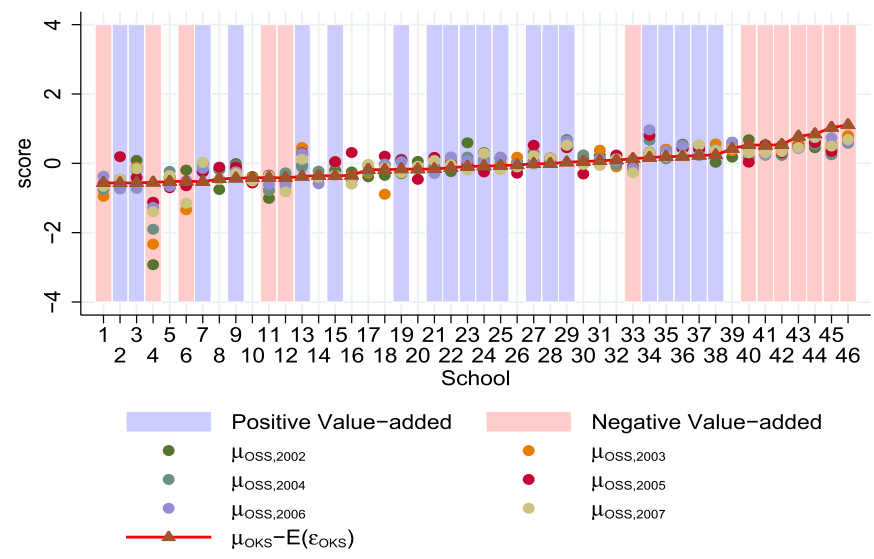

Fig. 12. Value-added: $\varepsilon^{h s} \sim N\left(0,-\widehat{\rho}-2 \sigma_{-\widehat{\rho}}\right)$.

Table 7

School choice: estimation results (Science High Schools).

\begin{tabular}{|c|c|c|c|c|}
\hline Variable & (OLS) & (2SLS) & (LIML) & (LIML) \\
\hline Number of available seats & $\begin{array}{l}0.034 \\
(0.030)\end{array}$ & $\begin{array}{l}0.032 \\
(0.031)\end{array}$ & $\begin{array}{l}0.032 \\
(0.034)\end{array}$ & $\begin{array}{l}0.037 \\
(0.036)\end{array}$ \\
\hline Average quantitative score in 2000 ÖSS & $\begin{array}{l}0.144 \\
(0.113)\end{array}$ & $\begin{array}{l}0.147 \\
(0.105)\end{array}$ & $\begin{array}{l}0.147 \\
(0.115)\end{array}$ & $\begin{array}{l}-0.070 \\
(0.135)\end{array}$ \\
\hline Average verbal score in 2000 ÖSS & $\begin{array}{l}-0.039 \\
(0.112)\end{array}$ & $\begin{array}{l}-0.037 \\
(0.106)\end{array}$ & $\begin{array}{l}-0.037 \\
(0.116)\end{array}$ & $\begin{array}{l}0.089 \\
(0.086)\end{array}$ \\
\hline Age & $\begin{array}{l}-0.0572 \\
(0.026)\end{array}$ & $\begin{array}{l}-0.0569 \\
(0.025)\end{array}$ & $\begin{array}{l}-0.0568 \\
(0.028)\end{array}$ & $\begin{array}{l}-0.044 \\
(0.026)\end{array}$ \\
\hline Minimum cutoff score & $\begin{array}{l}0.928^{* * * *} \\
(0.057)\end{array}$ & $\begin{array}{l}0.923^{* * * *} \\
0.064)\end{array}$ & $\begin{array}{l}0.922^{* * * * *} \\
(0.074)\end{array}$ & $\begin{array}{l}0.973^{* \ldots+*} \\
(0.068)\end{array}$ \\
\hline Value-added & & & & $\begin{array}{l}0.0930 \\
(0.036)\end{array}$ \\
\hline Constant & $\begin{array}{l}0.006 \\
(0.028)\end{array}$ & $\begin{array}{l}0.007 \\
(0.028)\end{array}$ & $\begin{array}{l}0.007 \\
(0.031)\end{array}$ & $\begin{array}{l}0.005 \\
(0.029)\end{array}$ \\
\hline$R^{2}$ & 0.973 & 0.973 & 0.973 & 0.977 \\
\hline$N$ & 38 & 38 & 38 & 38 \\
\hline
\end{tabular}

Note: Corrected standard errors are reported in parentheses.

** Significance at the 0.95 level.

* Significance at the 0.90 level.

*** Significance at the 0.99 level.

the last column indicate that the valuation of a school is very closely related to its minimum cutoff score. A one standard deviation increase in minimum cutoff score increases the valuation of the school by 0.96 standard deviation. While the value added of the school does seem to drive valuations, it seems less important. A one standard deviation increase in the value-added of the school increases its valuation by around 0.09 standard deviation.

These results show that there is reason to think that the circular causation hypothesis has some merit. Although more selective schools need not have a significant effect on their students' test scores, students value selectivity! It is also important to note that we are only investigating the effect of exam schools on academic achievement. However, students attending exam schools may have other benefits that are valuable to them, but unobservable to us. ${ }^{40}$ For example, it may be the case that more selective schools add value in terms of future earnings through the network students access by being in these schools. ${ }^{41}$

\footnotetext{
${ }^{40}$ Alstadsæter (2011) and Jacob et al. (2011) show the importance of the role of consumption value in students' school choices in different contexts.

${ }^{41}$ We should also note that school value-added includes several factors: some of these are under the control of school administrators and some are not. Raudenbush (2004) divide these factors into two groups "school context" which cannot be controlled by school administrators and "school practice" on which teachers and school administrators have some influence. If value-added estimates reflect the effect of school context, it would not be fair to keep schools accountable. However, in this section the schools that we analyze are similar in terms of "school context", so that our value-added estimates are likely to be driven by "school practice" rather than "school context".
} 


\section{Conclusion}

Schools are hard to evaluate in the real world. Unlike most experience goods, where consumers can know how much they like the good upon consuming it, with schooling, liking the experience is only part of what people care about. They care about attributes, like reputation or selectivity that might signal something, as well as the value-added by the teaching in the school. Since consumers are unlikely to have information about the latter, even if they have information about the former, information frictions are likely to be rampant in this market. This may well result in the market working poorly. Schools with high value-added may thus be ranked below those that are adding little value but are very selective.

School choice programs are thought to increase the productivity of public schools by encouraging competition in the market. Just like firms producing better products can charge a higher price for them, it is tempting to think of schools competing in their products with good schools delivering a better product, i.e., adding more value to their students, and as a result being more selective and having greater status. However, as argued above, quality is hard to infer in this market. As a result, the market may work poorly if quality information is not made available. In this paper, we use data available from public sources to show that, indeed, consumers value academic success on the university entrance exam, the selectivity of the school, elite school status and location, as well as the value-added of the school. However, value added seems to matter a lot less than selectivity. These results suggest that it is hard for families/students to infer the quality of a school as they tend to only see its selectivity and/or the performance of its students and cannot infer value added on this basis. As a result they associate selectivity with quality which we shown is often not the case. Providing information on value-added by a school is essential to the market working well in this domain.

Finally, our results illustrate the value of taking a structural, model based approach. First, as is well understood, by using the model, one can do more with less data. Second, even if we had better data, we would still need to correct for much of what we describe above. For example, if we had data at the student level on high school and university entrance exams, just looking at the difference in student performance by school would not give a bias free estimate of value added. Mean reversion as above would still be an issue. Its extent depends on the signal used and the extent of noise in the signal as explained above. If U.S. schools use a host of factors in deciding on their admissions, not just high school performance or SAT scores, the noise in their admissions could rise, worsening mean reversion bias. However, if preferences are horizontal more than vertical, as may well be the case in a large country like the U.S. where schools find a niche for themselves, the extent of mean reversion bias could be lower. Thus, preferences, the allocation system, and the strength of the signal present in the scores are critical inputs when developing measures of value added. They can only be obtained by taking a structural approach.

\section{Acknowledgments}

We would like to thank Nikhil Agarwal, Verónica Frisancho, Paul Grieco, Susumu Imai, Sung Jae Jun, Corinne Jones, Mark Roberts and Cemile Yavas for comments on an earlier draft. We would also like to thank participants of the CES-IFO Area Conference on Applied Microeconomics 2013 and the Penn State Applied Econ Conference 2013 for their useful comments on an earlier draft. We benefited from the helpful comments of seminar participants at University of Kentucky and Warwick University. All errors are our own.

\section{A.1. Cameron and Kim (2001)}

Suppose that $\varepsilon_{1}$ and $\varepsilon_{2}$ are jointly distributed with bivariate extreme value distribution

$$
H\left(\varepsilon_{1}, \varepsilon_{2}\right)=\exp \left(-\left(\exp \left(-\frac{\varepsilon_{1}}{\lambda}\right)+\exp \left(-\frac{\varepsilon_{2}}{\lambda}\right)\right)^{\lambda}\right)
$$

Cameron and Kim (2001) propose that

$$
\varepsilon_{1}=a \xi+b v_{1}+c \varepsilon_{2}=a \xi+b v_{2}+c
$$

where $\xi, v_{1}, v_{2}$ are independently distributed with extreme value distribution, and $a, b$ and $c$ are the weights that match the moments of extreme value distribution:

$$
E\left(\varepsilon_{i}\right)=E\left(a \xi+b v_{1}+c\right)=a \gamma+b \gamma+c=\gamma \operatorname{Var}\left(\varepsilon_{i}\right)=a^{2} \frac{\pi^{2}}{6}+b^{2} \frac{\pi^{2}}{6}=\frac{\pi^{2}}{6} \operatorname{Corr}\left(\varepsilon_{1}, \varepsilon_{2}\right)=\left[1-\lambda^{2}\right]=\frac{a^{2}}{a^{2}+b^{2}}
$$

This results in

$$
a=\sqrt{1-\lambda^{2}} b=\sqrt{1-a^{2}} c=(1-a-b) \gamma
$$

where $\gamma$ is the Euler constant.

This method is generalized to the multivariate extreme value distribution, 


$$
H\left(\varepsilon_{i 0}, \varepsilon_{i 1}, \ldots, \varepsilon_{i N}\right)=\exp \left(-\sum_{k=1}^{K}\left(\sum_{j \in B_{k}} \exp \left(-\frac{\varepsilon_{i j}}{\lambda_{k}}\right)\right)^{\lambda_{k}}\right)
$$

such that

Table A1

Correlation in minimum cutoff scores.

\begin{tabular}{llllll}
\hline Min score & 2000 & 2001 & 2002 & 2003 & 2004 \\
\hline 2000 & 1 & 0.98 & 0.97 & 0.96 & 0.96 \\
2001 & 0.98 & 0.97 & 0.99 & 0.95 \\
2002 & 0.97 & 0.96 & 0.99 & 1 & 0.97 \\
2003 & 0.96 & 0.95 & 0.97 & 0.98 \\
2004 & 0.96 & 1 & \\
\hline
\end{tabular}

Source: Science, Anatolian and Anatolian Teacher Training high school's cutoff scores from 2000 to 2004 from the Ministry of Education website.

Table A2

Correlation in maximum cutoff scores.

\begin{tabular}{llllll}
\hline Max score & 2000 & 2001 & 2002 & 2003 \\
\hline 2000 & 1 & 0.82 & 0.82 & 0.82 \\
2001 & 0.82 & 1 & 0.8 & 0.81 \\
2002 & 0.82 & 0.82 & 0.87 & 0.87 \\
2003 & 0.82 & 0.77 & 0.84 & 0.84 \\
2004 & 0.81 & 0.86 & & 0.86 \\
\hline
\end{tabular}

Source: Science, Anatolian and Anatolian Teacher Training high school's cutoff scores from 2000 to 2004 from the Ministry of Education website.

Table A3

Correlation in rank of minimum cutoff scores.

\begin{tabular}{llllll}
\hline Rank of Min score & 2000 & 2001 & 2002 & 2003 & 2004 \\
\hline 2000 & 1 & 0.94 & 0.94 & 0.94 & 0.97 \\
2001 & 0.94 & 1 & 1 & 0.99 & 0.94 \\
2002 & 0.94 & 0.98 & 0.99 & 1 & 0.98 \\
2003 & 0.94 & 0.97 & 0.98 & 0.98 \\
2004 & 0.94 & 0.97 & 1 \\
\hline
\end{tabular}

Source: Science, Anatolian and Anatolian Teacher Training high school's cutoff scores from 2000 to 2004 from the Ministry of Education website.

Table A4

Correlation in rank of maximum cutoff scores.

\begin{tabular}{|c|c|c|c|c|c|}
\hline Rank of Max score & 2000 & 2001 & 2002 & 2003 & 2004 \\
\hline 2000 & 1 & 0.76 & 0.77 & 0.78 & 0.75 \\
\hline 2001 & 0.76 & 1 & 0.8 & 0.83 & 0.78 \\
\hline 2002 & 0.77 & 0.8 & 1 & 0.82 & 0.79 \\
\hline 2003 & 0.78 & 0.83 & 0.82 & 1 & 0.84 \\
\hline 2004 & 0.75 & 0.78 & 0.79 & 0.84 & 1 \\
\hline
\end{tabular}

Source: Science, Anatolian and Anatolian Teacher Training high school's cutoff scores from 2000 to 2004 from the Ministry of Education website.

Table A5

Correlation in number of seats.

\begin{tabular}{lllll}
\hline Number of seats & 2000 & 2001 & 2002 & 2003 \\
\hline 2000 & 1 & 0.82 & 0.67 & 0.72 \\
2001 & 0.82 & 1 & 0.7 & 0.73 \\
2002 & 0.67 & 0.72 & 0.72 & 0.87 \\
2003 & 0.71 & 0.73 & 0.84 & 0.91 \\
2004 & 0.7 & 0.72 & 0.91 & 0.91 \\
\hline
\end{tabular}

Source: Science, Anatolian and Anatolian Teacher Training high school's cutoff scores from 2000 to 2004 from the Ministry of Education website. 
Table A6

Descriptive statistics: high school entrance exam.

\begin{tabular}{|c|c|c|c|c|c|}
\hline Variable & Obs & Mean & Std.Dev. & Min & Max \\
\hline \multicolumn{6}{|l|}{ Anatolian High Schools in Ankara } \\
\hline Number of available seats & 24 & 85.000 & 49.782 & 30 & 240 \\
\hline Minimum cutoff score & 24 & 813.573 & 30.792 & 768.819 & 872.254 \\
\hline Maximum cutoff score & 24 & 859.001 & 21.543 & 825.171 & 912.31 \\
\hline Age & 24 & 10.292 & 6.182 & 5 & 30 \\
\hline Average math score in 2000 ÖSS $^{\mathrm{a}}$ & 17 & 29.071 & 3.598 & 23.07 & 34.84 \\
\hline Average science score in 2000 ÖSS $^{\mathrm{a}}$ & 17 & 18.425 & 6.691 & 3.1 & 28.41 \\
\hline Average Turkish score in 2000 ÖSS $^{\mathrm{a}}$ & 17 & 34.656 & 1.857 & 31.35 & 37.81 \\
\hline Average social science score in 2000 ÖSS $^{a}$ & 17 & 25.920 & 2.477 & 21.78 & 30.21 \\
\hline Language offered: English & 24 & 0.792 & 0.415 & 0 & 1 \\
\hline Language offered: German & 24 & 0.167 & 0.381 & 0 & 1 \\
\hline Language offered: French & 24 & 0.042 & 0.204 & 0 & 1 \\
\hline Dormitory availability & 24 & 0.167 & 0.381 & 0 & 1 \\
\hline \multicolumn{6}{|l|}{ Anatolian High Schools in İstanbul } \\
\hline Number of available seats & 38 & 100.658 & 48.186 & 30 & 240 \\
\hline Minimum cutoff score & 38 & 827.916 & 41.686 & 654.059 & 898.332 \\
\hline Maximum cutoff score & 38 & 874.426 & 23.135 & 830.076 & 933.735 \\
\hline Age & 38 & 10.105 & 6.501 & 1 & 26 \\
\hline Average math score in 2000 ÖSS $^{\mathrm{a}}$ & 23 & 29.201 & 4.152 & 18.72 & 37.61 \\
\hline Average science score in 2000 ÖSS $^{\mathrm{a}}$ & 23 & 19.553 & 4.568 & 11.85 & 32.48 \\
\hline Average Turkish score in 2000 ÖSS $^{\mathrm{a}}$ & 23 & 35.819 & 2.524 & 29.19 & 41.05 \\
\hline Average social science score in 2000 ÖSS $^{a}$ & 23 & 26.359 & 3.446 & 20.83 & 34.74 \\
\hline Language offered: English & 38 & 0.763 & 0.431 & 0 & 1 \\
\hline Language offered: German & 38 & 0.184 & 0.393 & 0 & 1 \\
\hline Language offered: French & 38 & 0.053 & 0.226 & 0 & 1 \\
\hline Dormitory availability & 38 & 0.184 & 0.393 & 0 & 1 \\
\hline \multicolumn{6}{|l|}{ Anatolian High Schools in İzmir } \\
\hline Number of available seats & 18 & 90.000 & 63.431 & 30 & 300 \\
\hline Minimum cutoff score & 18 & 810.994 & 32.805 & 762.369 & 878.236 \\
\hline Maximum cutoff score & 18 & 868.863 & 30.033 & 818.16 & 915.172 \\
\hline Age & 18 & 14.500 & 16.111 & 1 & 48 \\
\hline Average math score in 2000 ÖSS $^{\mathrm{a}}$ & 12 & 26.553 & 6.916 & 12.61 & 31.03 \\
\hline Average science score in 2000 ÖSS $^{\mathrm{a}}$ & 12 & 17.968 & 4.550 & 9.45 & 22.17 \\
\hline Average Turkish score in 2000 ÖSS $^{\text {a }}$ & 12 & 33.875 & 4.792 & 24.02 & 37.48 \\
\hline Average social science score in 2000 ÖSS $^{\text {a }}$ & 12 & 25.014 & 5.621 & 14.59 & 33.3779 \\
\hline Language offered: English & 18 & 0.556 & 0.511 & 0 & 1 \\
\hline Language offered: German & 18 & 0.278 & 0.461 & 0 & 1 \\
\hline Language offered: French & 18 & 0.167 & 0.383 & 0 & 1 \\
\hline Dormitory availability & 18 & 0.278 & 0.461 & 0 & 1 \\
\hline \multicolumn{6}{|l|}{ Science High Schools } \\
\hline Number of available seats & 48 & 83.000 & 21.556 & 48 & 96 \\
\hline Minimum cutoff score & 48 & 878.010 & 18.120 & 837.949 & 920.268 \\
\hline Maximum cutoff score & 48 & 910.355 & 14.484 & 879.825 & 941.566 \\
\hline Age & 48 & 8.250 & 6.380 & 1 & 38 \\
\hline Average math score in 2000 ÖSS $^{\mathrm{a}}$ & 38 & 37.270 & 2.652 & 29.22 & 41.4 \\
\hline Average science score in 2000 ÖSS $^{\mathrm{a}}$ & 38 & 32.973 & 3.919 & 22.54 & 39.59 \\
\hline Average Turkish score in 2000 ÖSS $^{a}$ & 38 & 35.945 & 3.908 & 26.07 & 41.35 \\
\hline Average social science score in 2000 ÖSS $^{\text {a }}$ & 38 & 27.843 & 6.209 & 12.92 & 38.06 \\
\hline Language offered: English & 48 & 1 & 0 & 1 & 1 \\
\hline Language offered: German & 48 & 0 & 0 & 0 & 0 \\
\hline Language offered: French & 48 & 0 & 0 & 0 & 0 \\
\hline Dormitory availability & 48 & 1 & 0 & 1 & 1 \\
\hline \multicolumn{6}{|l|}{ Anatolian Teacher Training High Schools } \\
\hline Number of available seats & 91 & 56.703 & 21.322 & 24 & 120 \\
\hline Minimum cutoff score & 91 & 798.716 & 35.943 & 712.758 & 864.296 \\
\hline Maximum cutoff score & 91 & 864.419 & 16.861 & 827.49 & 902.864 \\
\hline Age & 91 & 8.571 & 3.763 & 1 & 12 \\
\hline Average math score in 2000 ÖSS $^{a}$ & 71 & 15.401 & 4.704 & 5.2 & 27.65 \\
\hline Average science score in 2000 ÖSS $^{\mathrm{a}}$ & 71 & 9.745 & 3.340 & 2.26 & 18.35 \\
\hline Average Turkish score in 2000 ÖSS $^{\mathrm{a}}$ & 71 & 31.726 & 3.405 & 22.65 & 37.87 \\
\hline Average social science score in 2000 ÖSS $^{\mathrm{a}}$ & 71 & 23.476 & 3.483 & 10.81 & 30.19 \\
\hline Language offered: English & 91 & 1 & 0 & 1 & 1 \\
\hline Language offered: German & 91 & 0 & 0 & 0 & 0 \\
\hline Language offered: French & 91 & 0 & 0 & 0 & 0 \\
\hline Dormitory availability & 91 & 0.846 & 0.363 & 0 & 1 \\
\hline
\end{tabular}

a The differences in the number of observations across variables comes from some schools being new so that there are no students graduating in 2000 . 
Table A7

Descriptive statistics: high school entrance exam scores.

\begin{tabular}{|c|c|c|c|c|c|c|c|c|}
\hline \multirow[t]{2}{*}{ Variable } & \multirow[t]{2}{*}{ Number of students } & \multirow[t]{2}{*}{ Mean } & \multirow[t]{2}{*}{ Std.Dev. } & \multicolumn{5}{|c|}{ Quantiles } \\
\hline & & & & Min & 0.25 & Median & 0.75 & $\operatorname{Max}$ \\
\hline OKS score & 553,495 & 592.35 & 86.34 & 442.53 & 526.76 & 572.83 & 637.44 & 941.49 \\
\hline
\end{tabular}

Table A8

Validity check: instrumental variables.

\begin{tabular}{|c|c|}
\hline Variable & Coefficients \\
\hline Number of available seats & $\begin{array}{l}0.084 \\
(0.061)\end{array}$ \\
\hline Average quantitative score in 2000 Öss & $\begin{array}{l}0.566 \\
(0.760)\end{array}$ \\
\hline Average verbal score in 2000 Öss & $\begin{array}{l}-0.045 \\
(1.177)\end{array}$ \\
\hline Age & $\begin{array}{l}0.235 \\
(0.404)\end{array}$ \\
\hline Science high school & $\begin{array}{l}58.04^{* \ldots * *} \\
(13.770)\end{array}$ \\
\hline Teacher high school & $\begin{array}{l}45.44^{* *} \\
(15.680)\end{array}$ \\
\hline Anatolian high school in İstanbul & $\begin{array}{l}23.770 \\
(16.330)\end{array}$ \\
\hline Anatolian high school in İzmir & $\begin{array}{l}11.400 \\
(16.910)\end{array}$ \\
\hline Education language - English & $\begin{array}{l}10.290 \\
(13.260)\end{array}$ \\
\hline Education language - German & $\begin{array}{l}-4.270 \\
(13.570)\end{array}$ \\
\hline Dormitory availability & $\begin{array}{l}12.530 \\
(6.809)\end{array}$ \\
\hline Ankara & $\begin{array}{l}26.41^{*} \\
(11.880)\end{array}$ \\
\hline İstanbul & $\begin{array}{l}23.57^{*} \\
(9.824)\end{array}$ \\
\hline İzmir & $\begin{array}{l}31.43^{* \ldots *} \\
(8.993)\end{array}$ \\
\hline Seats in worse schools & $\begin{array}{l}0.002 \\
(0.002)\end{array}$ \\
\hline Seats in better schools & $\begin{array}{l}-0.00443^{*} \\
(0.002)\end{array}$ \\
\hline Residual from min regression & $\begin{array}{l}0.744^{* * * *} \\
(0.090)\end{array}$ \\
\hline Constant & $\begin{array}{l}755.8^{* * * *} \\
(51.700)\end{array}$ \\
\hline$R^{2}$ & 0.804 \\
\hline$N$ & 161 \\
\hline
\end{tabular}

Note: Standard errors are reported in parentheses.

* Significance at the 0.90 level.

** Significance at the 0.95 level.

**** Significance at the 0.99 level.

$$
\varepsilon_{j}=a_{k} \xi+b_{k} v_{j}+c_{k}
$$

where

$$
a_{k}=\sqrt{1-\lambda_{k}^{2}}, \quad b_{k}=\sqrt{1-a_{k}^{2}}, \quad c_{k}=\left(1-a_{k}-b_{k}\right) \gamma
$$


Table A9

First stage estimation (only with "Residual from min regression" instrument).

\begin{tabular}{|c|c|}
\hline Variable & Coefficients \\
\hline Number of available seats & $\begin{array}{l}0.0796 \\
(0.0619)\end{array}$ \\
\hline Average quantitative score in 2000 ÖSS & $\begin{array}{l}1.745^{* * * *} \\
(0.46) 7\end{array}$ \\
\hline Average verbal score in 2000 ÖSS & $\begin{array}{l}2.401 \\
(0.442)\end{array}$ \\
\hline Age & $\begin{array}{l}0.292 \\
(0.404)\end{array}$ \\
\hline Science high school & $\begin{array}{l}51.90 \\
(14.43)\end{array}$ \\
\hline Teacher high school & $\begin{array}{l}36.57 \\
(15.61)\end{array}$ \\
\hline Anatolian high school in İstanbul & $\begin{array}{l}20.65 \\
(17.37)\end{array}$ \\
\hline Anatolian high school in İzmir & $\begin{array}{l}11.76 \\
(19.3)\end{array}$ \\
\hline Education language - English & $\begin{array}{l}11.38 \\
(14)\end{array}$ \\
\hline Education language - German & $\begin{array}{l}-6.202 \\
(14.41)\end{array}$ \\
\hline Dormitory Availability & $\begin{array}{l}15.19^{*} \\
(6.888)\end{array}$ \\
\hline Ankara & $\begin{array}{l}20.46 \\
(12.35)\end{array}$ \\
\hline İstanbul & $\begin{array}{l}21.50^{*} \\
(10.52)\end{array}$ \\
\hline İzmir & $\begin{array}{l}27.92^{*} \\
(11.96)\end{array}$ \\
\hline Residual from min regression & $\begin{array}{l}0.751^{* * * *} \\
(0.0864)\end{array}$ \\
\hline Constant & $\begin{array}{l}648.6 \\
(23.45)\end{array}$ \\
\hline$F$-stat (Excluded Variables) & 75.5603 \\
\hline$R^{2}$ & 0.7956 \\
\hline$N$ & 161 \\
\hline
\end{tabular}

Note: Standard errors are reported in parentheses.

** Significance at the 0.95 level.

* Significance at the 0.90 level.

*** Significance at the 0.99 level.

\section{A.2. Stability of exam schools' cutoff scores}

The following tables show the correlation of cutoff scores over the five year period from 2000 to 2004. As Tables A1 and A2 show the correlation between minimum cutoff scores over the years is never less than 0.95 . The correlation between maximum cutoff scores is lower than that between minimum cutoff scores, but it is still around 0.8. Similarly we also look at how the ranks of schools with respect to their minimum and maximum scores are correlated over time. Table A3 shows the correlation in rank of schools' minimum cutoff scores over the five-year period. Similarly, Table A4 shows the corresponding table for the maximum cutoff scores. These tables show that exam schools' cutoff scores are stable in Turkey.

Table A5 presents the correlation of number of available seats over the five-year period. The correlations in number of seats are never less than 0.8 for the consecutive years, which is consistent with the fact that the number of seats in a school in a year is decided based on the number of available classrooms, and teachers. In addition, the maximum classroom size in exam schools is defined by rules. These factors make it hard to change the size of the incoming class in the short term.

Next, we see if there is any evidence that schools respond to positive demand shocks by increasing their number of seats. Even if this is so, because schools decide on the number of students they will admit before they know today's demand shock, they can only respond to higher demand in the next year. Thus, today's demand shock and seats are unlikely to be correlated.

In any case, we look at what drives seats tomorrow. To do so, we first predict school cutoffs (a measure of their selectivity) by using the number of seats in the school, and school level and time fixed effects:

$$
\underline{c}_{j t}=\gamma_{1} I_{j}+\gamma_{2} I_{t}+q_{j t}+u_{j t}
$$

We then calculate the difference between observed and predicted selectivity $\left(c_{j t}-\hat{c}_{j t}\right)$, i.e., the demand shock. If schools respond to a positive demand shock by increasing their number of seats, then the change in the number of seats from time $t$ to $t+1$, $\left(q_{j(t+1)} q_{j t}\right)$, should be positively correlated with the difference between observed and predicted minimum cutoff scores at time $t$ : 
Table A10

School choice: estimation results (only with "Residual from min regression" instrument).

\begin{tabular}{|c|c|c|c|c|}
\hline Variable & (OLS) & (OLS) & (2SLS) & (LIML) \\
\hline Number of available seats & $\begin{array}{l}0.005 \\
(0.007)\end{array}$ & $\begin{array}{l}0.00842^{*} \\
(0.004)\end{array}$ & $\begin{array}{l}0.007 \\
(0.004)\end{array}$ & $\begin{array}{l}0.007 \\
(0.004)\end{array}$ \\
\hline Average quantitative score in 2000 ÖSS & $\begin{array}{l}0.218^{\text {*** }} \\
(0.053)\end{array}$ & $\begin{array}{l}0.0680^{*} \\
(0.033)\end{array}$ & $\begin{array}{l}0.111^{*} \\
(0.036)\end{array}$ & $\begin{array}{l}0.111^{* * *} \\
(0.036)\end{array}$ \\
\hline Average verbal score in 2000 ÖsS & $\begin{array}{l}0.306^{\text {*** }} \\
(0.053)\end{array}$ & $\begin{array}{l}0.0865 \\
(0.038)\end{array}$ & $\begin{array}{l}0.150^{*} \\
(0.039)\end{array}$ & $\begin{array}{l}0.150^{* * * *} \\
(0.039)\end{array}$ \\
\hline Age & $\begin{array}{l}0.026 \\
(0.062)\end{array}$ & $\begin{array}{l}0.032 \\
(0.031)\end{array}$ & $\begin{array}{l}0.030 \\
(0.039)\end{array}$ & $\begin{array}{l}0.030 \\
(0.039)\end{array}$ \\
\hline Science high school & $\begin{array}{l}8.422^{\text {**** }} \\
(1.764)\end{array}$ & $\begin{array}{l}3.237^{* * * *} \\
(0.765)\end{array}$ & $\begin{array}{l}4.736^{* \ldots *} \\
(1.012)\end{array}$ & $\begin{array}{l}4.736^{* * * *} \\
(1.012)\end{array}$ \\
\hline Teacher high school & $\begin{array}{l}4.039^{*} \\
(1.931)\end{array}$ & $\begin{array}{l}0.867 \\
(0.763)\end{array}$ & $\begin{array}{l}1.784 \\
(1.030)\end{array}$ & $\begin{array}{l}1.784 \\
(1.030)\end{array}$ \\
\hline Anatolian high school in İstanbul & $\begin{array}{l}1.928 \\
(2.152)\end{array}$ & $\begin{array}{l}-0.544 \\
(0.728)\end{array}$ & $\begin{array}{l}0.171 \\
(1.117)\end{array}$ & $\begin{array}{l}0.171 \\
(1.117)\end{array}$ \\
\hline Anatolian high school in İzmir & $\begin{array}{l}1.715 \\
(2.280)\end{array}$ & $\begin{array}{l}0.392 \\
(0.679)\end{array}$ & $\begin{array}{l}0.774 \\
(0.987)\end{array}$ & $\begin{array}{l}0.774 \\
(0.987)\end{array}$ \\
\hline Education language - English & $\begin{array}{l}2.671 \\
(2.192)\end{array}$ & $\begin{array}{c}-0.028 \\
(1.118)\end{array}$ & $\begin{array}{l}0.752 \\
(1.381)\end{array}$ & $\begin{array}{l}0.752 \\
(1.381)\end{array}$ \\
\hline Education language - German & $\begin{array}{l}1.198 \\
(2.254)\end{array}$ & $\begin{array}{l}0.330 \\
(1.175)\end{array}$ & $\begin{array}{l}0.581 \\
(1.424)\end{array}$ & $\begin{array}{l}0.581 \\
(1.424)\end{array}$ \\
\hline Dormitory availability & $\begin{array}{l}1.617 \\
(0.893)\end{array}$ & $\begin{array}{l}0.500 \\
(0.455)\end{array}$ & $\begin{array}{l}0.823 \\
(0.544)\end{array}$ & $\begin{array}{l}0.823 \\
(0.544)\end{array}$ \\
\hline Ankara & $\begin{array}{l}4.235^{* * *} \\
(1.494)\end{array}$ & $\begin{array}{l}0.733 \\
(0.485)\end{array}$ & $\begin{array}{l}1.745^{*} \\
(0.754)\end{array}$ & $\begin{array}{l}1.745^{*} \\
(0.754)\end{array}$ \\
\hline İstanbul & $\begin{array}{l}4.485^{\text {**** }} \\
(1.297)\end{array}$ & $\begin{array}{l}1.687^{* * *} \\
(0.522)\end{array}$ & $\begin{array}{l}2.496 \\
(0.749)\end{array}$ & $\begin{array}{l}2.496^{*} \\
(0.749)\end{array}$ \\
\hline İzmir & $\begin{array}{l}3.746 \\
(1.449)\end{array}$ & $\begin{array}{l}0.608 \\
(0.381)\end{array}$ & $\begin{array}{l}1.515^{* * *} \\
(0.552)\end{array}$ & $\begin{array}{l}1.515^{* *} \\
(0.552)\end{array}$ \\
\hline Minimum cutoff score & & $\begin{array}{l}0.0846^{* * * *} \\
(0.006)\end{array}$ & $\begin{array}{l}0.0602^{* * * *} \\
(0.008)\end{array}$ & $\begin{array}{l}0.0602^{\text {****** }} \\
(0.008)\end{array}$ \\
\hline Constant & $\begin{array}{l}-22.95^{* * * *} \\
(3.121)\end{array}$ & $\begin{array}{l}-76.18^{* * * *} \\
(4.363)\end{array}$ & $\begin{array}{l}-60.80^{* \ldots * *} \\
(4.958)\end{array}$ & $\begin{array}{l}-60.80^{* * *} \\
(4.958)\end{array}$ \\
\hline$N$ & 161 & 161 & 161 & 161 \\
\hline$R^{2}$ & 0.807 & 0.942 & 0.923 & 0.923 \\
\hline
\end{tabular}

Note: Corrected standard errors are reported in parentheses.

* Significance at the 0.90 level.

** Significance at the 0.95 level.

**** Significance at the 0.99 level.

Table A11

School choice: estimation results (Science High Schools).

\begin{tabular}{|c|c|c|c|c|}
\hline Variable & (OLS) & (2SLS) & (LIML) & (LIML) \\
\hline Number of available seats & $\begin{array}{l}0.005 \\
(0.005)\end{array}$ & $\begin{array}{l}0.005 \\
(0.005)\end{array}$ & $\begin{array}{l}0.005 \\
(0.005)\end{array}$ & $\begin{array}{l}0.006 \\
(0.005)\end{array}$ \\
\hline Average quantitative score in 2000 ÖSS & $\begin{array}{l}0.146 \\
(0.115)\end{array}$ & $\begin{array}{l}0.144 \\
(0.106)\end{array}$ & $\begin{array}{l}0.144 \\
(0.115)\end{array}$ & $\begin{array}{l}-0.075 \\
(0.139)\end{array}$ \\
\hline Average verbal score in 2000 ÖSS & $\begin{array}{l}-0.026 \\
(0.075)\end{array}$ & $\begin{array}{l}-0.026 \\
(0.070)\end{array}$ & $\begin{array}{l}-0.026 \\
(0.076)\end{array}$ & $\begin{array}{l}0.059 \\
(0.057)\end{array}$ \\
\hline Age & $\begin{array}{l}-0.0300 \\
(0.014)\end{array}$ & $\begin{array}{l}-0.0302^{*} \\
(0.013)\end{array}$ & $\begin{array}{l}-0.0302^{*} \\
(0.014)\end{array}$ & $\begin{array}{l}-0.023 \\
(0.014)\end{array}$ \\
\hline Minimum cutoff score & $\begin{array}{l}0.167^{\text {***** }} \\
(0.010)\end{array}$ & $\begin{array}{l}0.167^{*} \\
(0.011)\end{array}$ & $\begin{array}{l}0.167^{\text {**.*.* }} \\
(0.012)\end{array}$ & $\begin{array}{l}0.175^{\text {**** }} \\
(0.011)\end{array}$ \\
\hline Value-added & & & & $\begin{array}{l}1.077^{*} \\
(0.424)\end{array}$ \\
\hline Constant & $\begin{array}{l}-142.8^{* * *} \\
(8.272)\end{array}$ & $\begin{array}{l}-143.3^{* * * *} \\
(8.289)\end{array}$ & $\begin{array}{l}-143.3^{\text {**** }} \\
(9.082)\end{array}$ & $\begin{array}{l}-145.5^{* * *} \\
(8.031)\end{array}$ \\
\hline$R^{2}$ & 0.973 & 0.973 & 0.973 & 0.977 \\
\hline$N$ & 38 & 38 & 38 & 38 \\
\hline
\end{tabular}

Note: Corrected standard errors are reported in parentheses.

${ }^{* *}$ Significance at the 0.95 level.

* Significance at the 0.90 level.

*** Significance at the 0.99 level. 


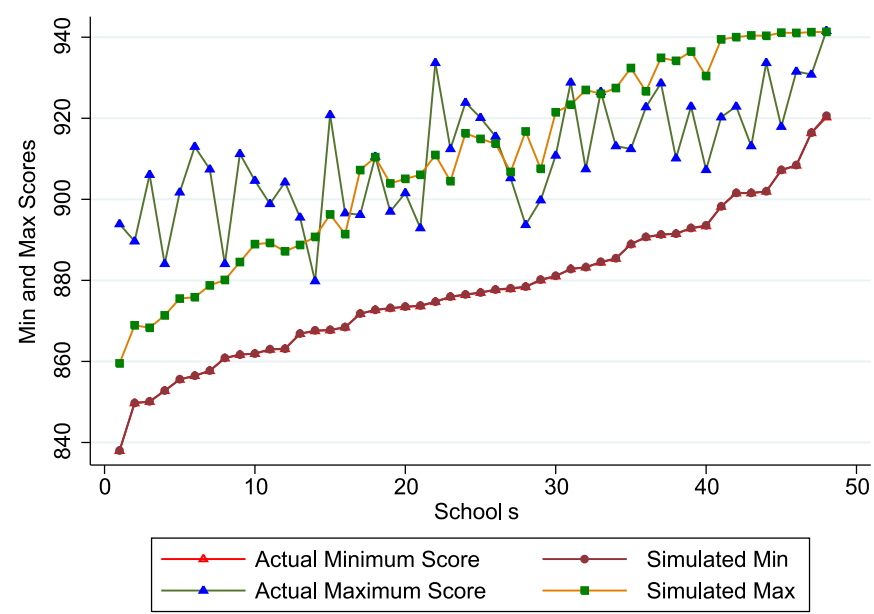

Fig. A1. Model fit: Science high schools nest.

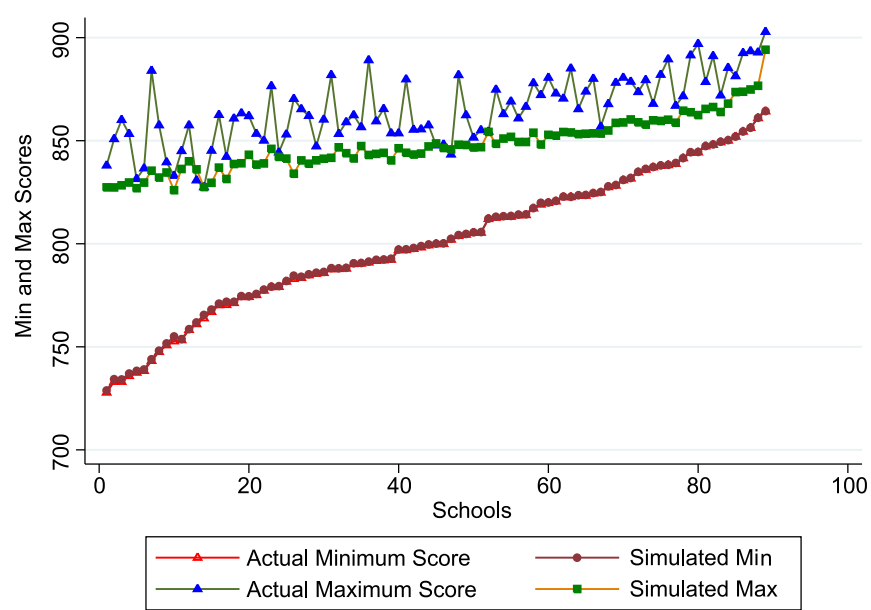

Fig. A2. Model fit: Teacher high schools nest.

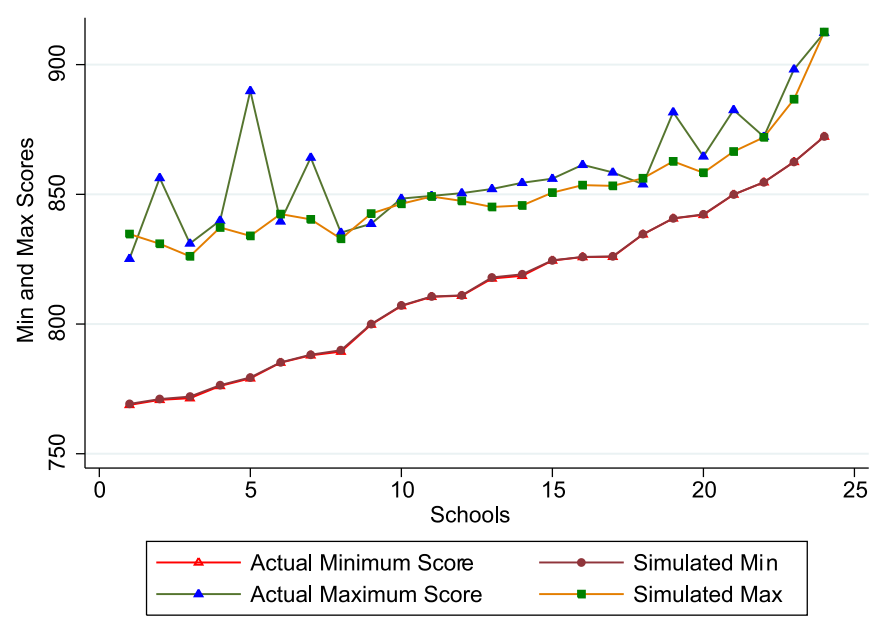

Fig. A3. Model fit: Ankara Anatolian high schools nest. 


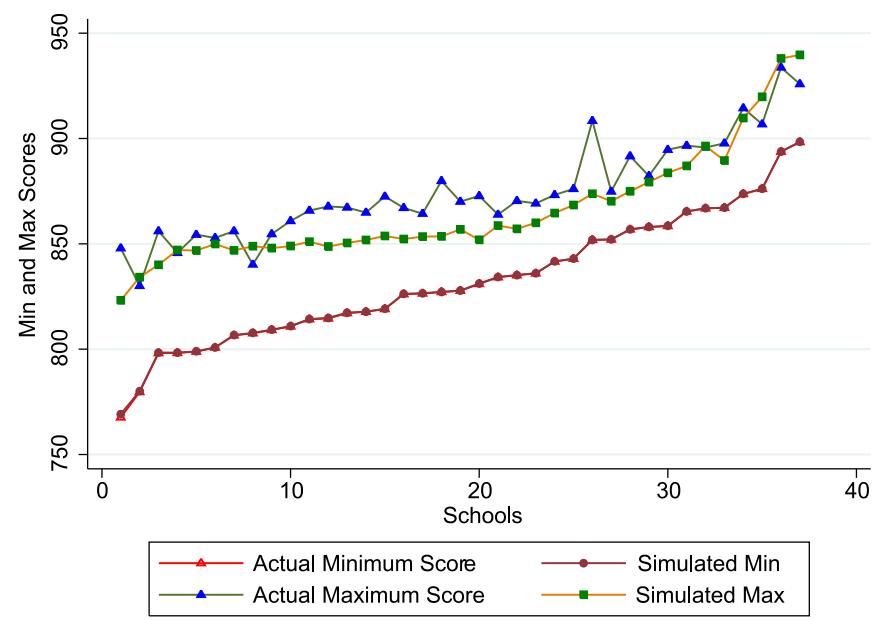

Fig. A4. Model fit: İstanbul Anatolian high schools nest.

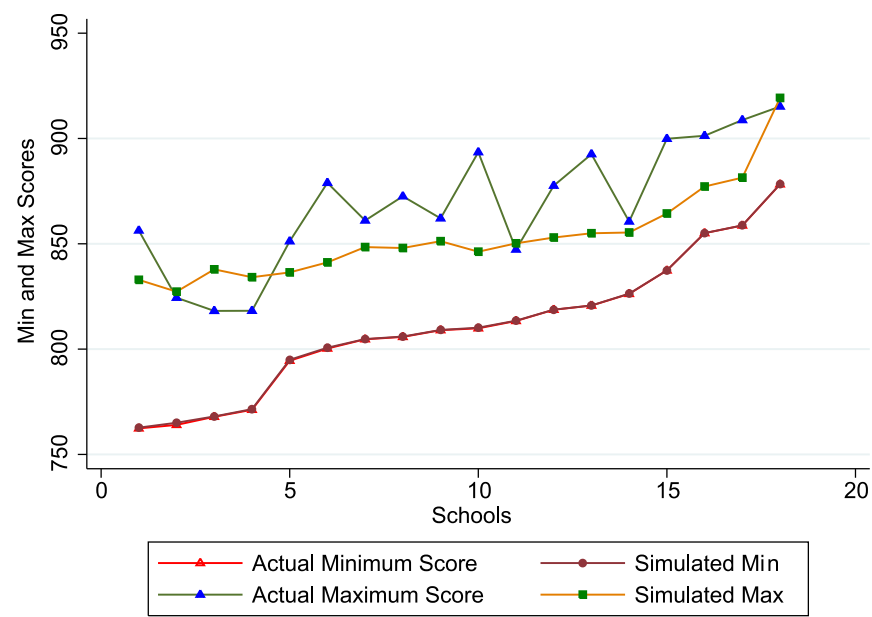

Fig. A5. Model fit: İzmir Anatolian high schools nest.

$\operatorname{Corr}\left(\left(\hat{c}_{j t}-c_{j t}\right),\left(q_{j(t+1)-} q_{j t}\right)\right)>0$

However, our estimates give a correlation of 0.0424 , which has a $P$ value of 0.028 . Though positive, this value is very small.

\section{A.3. Additional tables and figures}

See Tables A6-A11 and Figs. A1-A5.

\section{Appendix B. Supplementary data}

Supplementary data associated with this article can be found in the online version at http://dx.doi.org/10.1016/j.euroecorev 2016.09.009.

\section{References}

Abdulkadiroğlu, A., Angrist, J., Pathak, P., 2014. The elite illusion: achievement effects at Boston and New York exam schools. Econometrica 82 (1), 137-196. Alstadsæter, A., 2011. Measuring the consumption value of higher education. CESifo Econ. Stud. 57 (3), $458-479$.

Bacher-Hicks, A., Kane, T.J., Staiger, D.O., 2014. Validating Teacher Effect Estimates Using Changes in Teacher Assignments in Los Angeles. Technical Report, National Bureau of Economic Research.

Berry, S.T., 1994. Estimating discrete-choice models of product differentiation. RAND J. Econ., $242-262$.

Bresnahan, T.F., Stern, S., Trajtenberg, M., 1997. Market segmentation and the sources of rents from innovation: personal computers in the late 1980s. RAND J. Econ., S17-S44.

Burgess, S., Greaves, E., Vignoles, A., Wilson, D., 2009. What Parents Want: School Preferences and School Choice. 
Cameron, A.C., Kim, N., 2001. Simulation Methods for Nested Logit Models. Department of Economics, University of California, Davis, California

Caner, A., Okten, C., 2013. Higher education in Turkey: subsidizing the rich or the poor? Econ. Educ. Rev. 35, 75-92.

Card, D., Giuliano, L., 2014. Does Gifted Education Work? For Which Students? Technical Report, National Bureau of Economic Research.

Chay, K.Y., McEwan, P.J., Urquiola, M., 2005. The central role of noise in evaluating interventions that use test scores to rank schools. Am. Econ. Rev. 95 (4), 1237-1258.

Chetty, R., Friedman, J.N., Rockoff, J.E., 2014a. Measuring the impacts of teachers II: teacher value-added and student outcomes in adulthood. Am. Econ. Rev. 104 (9), 2633-2679.

Chetty, R., Friedman, J.N., Rockoff, J.E., 2014b. Prior Test Scores do not Provide Valid Placebo Tests of Teacher Switching Research Designs.

Chetty, R., Friedman, J., Rockoff, J.E., 2015. Measuring the Impacts of Teachers: Response to Rothstein (2014).

Clark, D., 2010. Selective schools and academic achievement. BE J. Econ. Anal. Policy 10, 1.

Cullen, J.B., Jacob, B.A., Levitt, S., 2006. The effect of school choice on participants: evidence from randomized lotteries. Econometrica 74 (5), 1191-1230.

Cullen, J.B., Jacob, B.A., Levitt, S.D., 2005. The impact of school choice on student outcomes: an analysis of the chicago public schools. J. Public Econ. 89 (5), 729-760.

Dale, S. Krueger, A.B., 2011. Estimating the Return to College Selectivity over the Career Using Administrative Earnings Data. Technical Report, National Bureau of Economic Research.

Dale, S.B., Krueger, A.B., 2002. Estimating the payoff to attending a more selective college: an application of selection on observables and unobservables. Q. J. Econ. 117 (4), 1491-1527.

Darling-Hammond, L., Amrein-Beardsley, A., Haertel, E., Rothstein, J., 2012. Evaluating teacher evaluation. Phi Delta Kappan 93 (6), 8-15.

Deming, D.J., 2014. Using school choice lotteries to test measures of school effectiveness. Am. Econ. Rev. 104 (5), $406-411$.

Dobbie, W., Fryer Jr, R.G., 2011. Exam High Schools and Academic Achievement: Evidence from New York City. Technical Report, National Bureau of Economic Research.

Duflo, E., Dupas, P., Kremer, M., 2011. Peer effects, teacher incentives, and the impact of tracking: evidence from a randomized evaluation in Kenya. Am. Econ. Rev. $101(5), 1739-1774$.

Fox, J.T., 2009. Structural empirical work using matching models. In: New Palgrave Dictionary of Economics, online edition.

Hastings, J., Kane, T., Staiger, D., 2008. Heterogeneous Preferences and the Efficacy of Public School Choice. NBER Working Paper, 2145.

Hastings, J.S., Neilson, C.A., Zimmerman, S.D., 2012. The Effect of School Choice on Intrinsic Motivation and Academic Outcomes. Technical Report, National Bureau of Economic Research.

Hoxby, C.M., 2000. The effects of class size on student achievement: new evidence from population variation. Q. J. Econ. 115 (4), $1239-1285$.

Jacob, B., McCall, B., Stange, K., 2011. The Consumption Value of Postsecondary Education (retrieved December 4, 2011).

Kirabo Jackson, C., 2010. Do students benefit from attending better schools? evidence from rule-based student assignments in trinidad and tobago. Econ. J. 120 (549), 1399-1429.

Koedel, C., Mihaly, K., Rockoff, J.E., 2015. Value-added modeling: a review. Econ. Educ. Rev. 47, $180-195$.

Krishna, K., Tarasov, A., 2013. Affirmative Action: One Size Does Not Fit All. Technical Report, National Bureau of Economic Research.

Ebenstein, A., Lavy, V., Roth, S., 2016. The long run economic consequences of high-stakes examinations: evidence from transitory variation in pollution. Am. Econ. J.: Appl. Econ. 84 (4), 36-65.

MacLeod, W.B., Urquiola, M., 2009. Anti-Lemons: School Reputation and Educational Quality. Technical Report, National Bureau of Economic Research.

Pop-Eleches, C., Urquiola, M., 2013. Going to a better school: effects and behavioral responses. Am. Econ. Rev. 103 (4), $1289-1324$.

Raudenbush, S.W., 2004. What are value-added models estimating and what does this imply for statistical practice? J. Educ. Behav. Stat. 29 (1), 121-129.

Rothstein, J., 2015. Revisiting the Impacts of Teachers.

Tansel, A., Bircan, F., 2006. Demand for education in Turkey: a Tobit analysis of private tutoring expenditures. Econ. Educ. Rev. 25 (3), $303-313$.

Todd, P.E., Wolpin, K.I., 2003. On the specification and estimation of the production function for cognitive achievement. Econ. J. 113 (485), F3-F33.

Train, K., 2009. Discrete Choice Methods with Simulation. Cambridge University Press.

Wooldridge, J.M., 1995. Selection corrections for panel data models under conditional mean independence assumptions. J. Econom. 68 (1), $115-132$.

Zimmerman, S., 2014. Making Top Managers: The Role of Elite Universities and Elite Peers. Technical Report. 